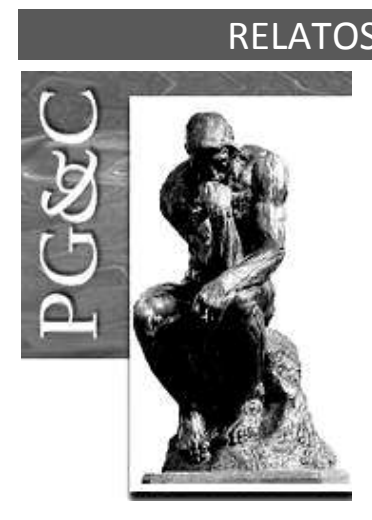

\title{
APLICAÇÃO DE COMPETÊNCIAS CIENTÍFICAS NO TRABALHO: UM ESTUDO NO BANCO DO BRASIL
}

\author{
Gerson Padilha de Almeida \\ Mestre em Gestão do Conhecimento e Tecnologia da Informação pela \\ Universidade Católica de Brasília, Brasil. \\ E-mail: gerson01@hotmail.com \\ Isa Aparecida de Freitas \\ Doutora em Psicologia pela Universidade de Brasília, Brasil. \\ E-mail: isapfreitas@gmail.com \\ Edilson Ferneda \\ Doutor em Computação pelo Laboratoire d'Informatique, Robotique et \\ Microélectronique de Montpellier, França. Professor da Universidade \\ Católica de Brasília, Brasil. \\ E-mail: eferneda@pos.ucb.com
}

\begin{abstract}
Resumo
Somente a formação escolar tradicional não consegue desenvolver as competências profissionais necessárias à realidade empresarial. A busca pelo conhecimento inovador, também ultrapassa os limites das universidades corporativas e encontra refúgio nos centros de excelência de criação do conhecimento e inovação que são as universidades, especificamente em seus cursos de mestrado e doutorado. Os profissionais que participam de mestrado ou doutorado desenvolvem, por meio da pesquisa acadêmica, conhecimentos, habilidades e atitudes científicas denominadas competências científicas. O objetivo deste estudo é verificar a aplicação de competências científicas no Banco do Brasil adquiridas por meio do seu programa de capacitação em nível stricto sensu. A partir das opiniões dos participantes do programa de capacitação do Banco do Brasil, coletadas via questionário, foram realizadas: (i) uma análise exploratória e descritiva dos dados, (ii) uma análise fatorial exploratória das variáveis referentes a cada constructo e de consistência interna dos fatores extraídos, (iii) uma análise de correlação para verificação da inter-relação entre os fatores e (iv) uma análise de regressão múltipla. Os resultados da pesquisa indicam que as competências científicas desenvolvidas pelos mestres e doutores são aplicadas no trabalho, tendo o suporte organizacional como fator preditivo para essa aplicação.
\end{abstract}

Palavras-chave: Educação Corporativa. Transferência de Aprendizagem. Competências Científicas.

\section{APPLICATION OF SCIENTIFIC COMPETENCES AT WORK: A STUDY AT THE BANCO DO BRASIL}

\begin{abstract}
Only the traditional school education cannot develop the professional competencies necessary to business reality. The search for new knowledge also push the boundaries of corporate universities and finds refuge in the knowledge and innovation creation centers that are the universities, specifically in their master's and doctoral courses. The professionals who participate in master's or doctoral develop, through academic research, knowledge, skills and scientific attitudes called scientific competencies. The goal of this study is to verify the application, in Banco do Brasil, of scientific competencies acquired
\end{abstract}

Perspectivas em Gestão \& Conhecimento, João Pessoa, v. 8, n. 1, p. 155-190, jan./abr. 2018. DOI: http://dx.doi.org/10.21714/2236-417X2018v8n1p155.

http://periodicos.ufpb.br/ojs2/index.php/pgc. ISSN: 2236-417X. Publicação sob Licença (cc) EY-Nc-ND 
through its training program in the strict sense level. Based on the opinions of the participants of Banco do Brasil training program, collected by means of a questionnaire, the following steps were performed: (i) an exploratory and descriptive data analysis, (ii) an exploratory factorial analysis of the variables for each construct and internal consistency of the extracted factors, (iii) a correlation analysis to verify the interrelationship between the factors, and (iv) a multiple regression analysis. The survey results indicate that the scientific competencies developed by teachers and doctors are applied at work, having organizational support as a predictive factor for this application.

Keywords: Corporate Education. Learning Transfer. Scientific competencies.

\section{INTRODUÇÃO}

No contexto atual de aceleração do desenvolvimento tecnológico, onde cresce a exigência por maiores níveis de produtividade, as organizações têm mostrado interesse cada vez maior por modelos de gestão que estimulem a aprendizagem, a adaptação e a inovação. Isto porque parece que a eficiência e a eficácia das organizações derivam de sua capacidade de desenvolver competências (conhecimentos, habilidades e atitudes - $\mathrm{CHA}$ ) e integrá-las em torno dos objetivos organizacionais (BRANDÃO; BAHRY, 2005).

Tanto no setor privado quanto no setor público, os pressupostos afetos à gestão por competências parecem já ter sido incorporados pelas empresas, fundamentando a prática gerencial. Isto porque o mercado de trabalho, cada vez mais dinâmico, complexo e competitivo, tem exigido profissionais capazes de agregar valor às organizações. O profissional almejado pelas instituições deve ser capaz de criticar a realidade a fim de transformá-la e com isso obter um diferencial competitivo capaz de tornar seus resultados sustentáveis. Isto se traduz na busca de inovação empresarial.

Uma vez que somente a formação acadêmica não consegue desenvolver as competências profissionais necessárias à realidade empresarial, que são muito diversificadas, as empresas também passaram a capacitar seus funcionários. Uma das formas encontradas para o desenvolvimento e a capacitação contínua desses profissionais foi a criação de universidades corporativas. Porém, a busca pelo conhecimento inovador também ultrapassa os limites das universidades corporativas e encontra refúgio nos centros de excelência de criação do conhecimento e inovação - universidades acadêmicas - especificamente em seus cursos de pós-graduação stricto sensu.

A formação de recursos humanos qualificados é considerada por vários autores como a mais importante função do ensino superior e estudos sobre inovação têm indicado, sistematicamente, a importância do sistema de ensino superior para a inovação tecnológica (VELHO, 2007). Entre os recursos humanos qualificados, destaque é dado àqueles treinados no nível de pós-graduação stricto sensu (mestres e doutores). Durante o curso de mestrado ou doutorado o aluno torna-se um pesquisador, adotando postura e métodos científicos para a construção de seu trabalho. Essa prática resulta no desenvolvimento de conhecimentos, habilidades e atitudes científicas, chamadas aqui de competências científicas. Com a conclusão do mestrado e doutorado, o pesquisador retorna ao ambiente empresarial, daí apresenta-se a seguinte questão: é possível fazer uso, no trabalho, das competências científicas desenvolvidas no ambiente acadêmico, especificamente, nos cursos de mestrado e doutorado?

A mera existência de mestres e doutores em uma empresa não gera benefícios de maneira automática (VELHO, 2007). Para que isso ocorra, algumas condições são necessárias, entre elas a aplicação, no trabalho, das competências científicas desenvolvidas nos referidos cursos.

Ao se fazer um recorte nas competências adquiridas pelos mestres e doutores ao

Perspectivas em Gestão \& Conhecimento, João Pessoa, v. 8, n. 1, p. 155-190, jan./abr. 2018. 
longo dos cursos de mestrado ou doutorado, focando nas competências científicas, seria de se verificar a aplicação dessas competências científicas no ambiente empresarial. No caso deste estudo, a empresa pesquisada foi o Banco do Brasil, que tem um alto investimento na capacitação de seus profissionais e conta com um programa de formação de mestres e doutores.

Em função desses investimentos, já foram realizadas duas avaliações sobre aplicação no trabalho das competências desenvolvidas pelos egressos dos programas de mestrado e doutorado (BAHRY; TOLFO, 2007; BRANDÃO; BAHRY; FREITAS, 2008). Este trabalho foi desenvolvido a partir desses dois estudos, mas diferentemente dos anteriores foca apenas os funcionários que participaram na condição de bolsistas, ou seja, aqueles que não se afastaram do trabalho durante a realização do curso.

O desenvolvimento de competências científicas pelos alunos de mestrado e doutorado transcende o interesse acadêmico, uma vez que expande a relevância do desenvolvimento destas competências também para outras áreas da sociedade, como as empresas.

\section{REVISÃO DA LLITERATURA}

\subsection{Educação corporativa}

Com o advento da era industrial, duas formas milenares de trabalho, a escravidão e a servidão, foram substituídas pelo trabalho assalariado. Para o trabalhador assalariado era necessária uma qualificação que o permitisse aprender e apreender as normas de seu ofício e o dotasse de certas qualidades para o trabalho nas indústrias, como a disciplina. Foi criada, para esses fins, a escola de educação básica gratuita e aberta a todos. Evidenciou-se a divisão do trabalho entre seus componentes intelectual e manual (MENINO, 2004). Ford, Fayol e Taylor foram os principais sistematizadores da organização do trabalho. O trabalho era organizado em hierarquia, divido em tarefas, com controle tempo, disciplina, fiscalização e concentração dos trabalhadores no local do processo de produção (fábrica). Porém, a partir da segunda metade do século $\mathrm{XX}$, diversos fatores tecnológicos, sociais, econômicos e estratégicos começaram a provocar alterações no modelo da sociedade industrial:

A troca de paradigma na gestão de empresas, a passagem da administração taylorista/fordista para a gestão flexível, gerou forte impacto no comportamento das organizações. Estruturas verticalizadas e altamente centralizadas cedem espaço para estruturas horizontalizadas e amplamente descentralizadas. A rígida divisão entre trabalho mental e manual tende a ser eliminada. Tarefas fragmentadas e padronizadas tornam-se integrais e complexas, exigindo, em todos os níveis organizacionais, pessoas com capacidade de pensar e executar simultaneamente (EBOLI, 2002. In: FLEURY, 2002, p. 187).

Desta forma, as empresas começam a estruturar áreas organizacionais capazes de entregar cursos ao público interno, habilidades específicas que enfatizassem necessidades individuais e sempre dentro do escopo tático (EBOLI, 2002). Porém, o ambiente empresarial passa a se caracterizar por profundas e frequentes mudanças e pela necessidade de respostas cada vez mais ágeis para garantir a sobrevivência das organizações. Consequentemente, também é exigido um novo perfil profissional dos colaboradores que enfatize o autodesenvolvimento e a aprendizagem contínua. Assim, as ações educacionais que enfatizam o conhecimento técnico e instrumental já não são mais suficientes para assegurar o desenvolvimento do perfil desses novos profissionais. É preciso que as empresas implantem

Perspectivas em Gestão \& Conhecimento, João Pessoa, v. 8, n. 1, p. 155-190, jan./abr. 2018. 
sistemas educacionais que privilegiem o desenvolvimento de atitudes, posturas e habilidades (EBOLI, 2002).

Ainda neste contexto, surge o advento e a consolidação da economia do conhecimento, na qual conhecimento é a nova base para a formação de riqueza nos níveis individual, empresarial ou nacional. Sendo assim, o conceito de Educação Corporativa surge no final do século XX. Segundo Meister (1999, p. 1-12), em essência, são cinco as forças que sustentaram o aparecimento desse fenômeno: organizações flexíveis (não hierarquizadas com capacidade de respostas rápidas); a era do conhecimento (economia do conhecimento); rápida obsolescência do conhecimento; empregabilidade e educação para estratégia global.

Segundo Eboli (2005, p. 48), a finalidade básica de um sistema de educação corporativa em uma organização é fomentar "o desenvolvimento e a instalação das competências empresariais e humanas consideradas críticas para a viabilização das estratégias de negócios", de uma forma sistemática, estratégica e contínua. Assim, os programas educacionais que eram restritos aos níveis gerenciais e à alta administração passam a ser ampliados, abrangendo com a educação todos os colaboradores da empresa. A prática dessas ações amplas, antes apenas pontuais a certos funcionários, marca a passagem do tradicional Centro de Treinamento e Desenvolvimento (T\&D) para novas modalidades de educação corporativa, concretizada por meio das universidades corporativas. Consequentemente, 0 comprometimento da empresa com a educação e o desenvolvimento dos seus colaboradores surge um novo caminho para a criação de vantagem competitiva sustentável.

A universidade corporativa surge como veículo eficaz para o alinhamento e desenvolvimento dos talentos humanos de acordo com as estratégias empresariais. Ela é, portanto, "um sistema de desenvolvimento de pessoas pautado pela gestão por competências. As universidades corporativas estão para o conceito de competência assim como os tradicionais centros de T\&D estiveram para o conceito de cargo" (EBOLI, 2002).

Sistemas de educação corporativa apresentam sete princípios de sucesso, "que dão um enfoque conceitual e metodológico para a concepção, a implementação e a análise de projetos de educação corporativa realizados nas organizações de modo geral" (EBOLI, 2004 p. 57-61). Estes princípios estão relacionados aos conceitos de Competitividade, Perpetuidade, Conectividade, Disponibilidade, Cidadania, Parceria (interna e externa) e Sustentabilidade. Ao se implementar uma universidade corporativa segundo tais princípios, espera-se algum retorno do investimento realizado pelas organizações, que não se restringe ao aspecto financeiro, mas também sob a ótica da aplicação da aprendizagem nos processos de trabalho. É neste contexto que o presente estudo abordará a aplicação das competências científicas desenvolvidas em cursos de mestrado e doutorado.

\subsubsection{Universidades corporativas}

A missão de uma universidade corporativa, segundo Eboli (2002), é "[...] formar e desenvolver os talentos humanos na gestão dos negócios, promovendo a gestão do conhecimento organizacional (geração, assimilação, difusão e aplicação), através de um processo de aprendizagem ativa e contínua". Os principais objetivos desse sistema, conforme a mesma autora, "são o desenvolvimento e a instalação das competências empresariais e humanas consideradas críticas para a viabilização das estratégias de negócios" (EBOLI, 2002).

É possível, conforme Brandão e Guimarães (2001), classificar as competências como humanas - aquelas relacionadas ao indivíduo ou à equipe de trabalho - ou organizacionais aquelas que dizem respeito à organização como um todo. Percebe-se uma articulação entre a educação corporativa, gestão por competências e gestão do conhecimento. Todos esses processos estão conectados pela aprendizagem, seja individual ou empresarial.

A aprendizagem representa o processo pelo qual se adquire competência, seja

Perspectivas em Gestão \& Conhecimento, João Pessoa, v. 8, n. 1, p. 155-190, jan./abr. 2018. 
organizacional ou humana (BRANDÃO, 2007). Já competência pode ser entendida como a combinação sinérgica de conhecimentos, habilidades e atitudes, expressas pelo desempenho profissional dentro de um contexto organizacional que agregam valor a pessoas e organizações (FREITAS; BRANDÃO, 2005).

Considerando que quando se fala de educação corporativa está-se falando de um processo intencional de geração e uso do conhecimento, convém destacar o que Davenport e Prusak (2003, p. 63) já alertaram: sem conhecimento, as organizações não poderiam se organizar e não conseguiriam manter-se funcionando. Segundo esses autores, existem cinco formas de gerar conhecimento dentro de uma organização, segundo Davenport e Prusak (2003): (i) Aquisição, aluguel ou financiamento: adquirir uma organização ou contratar indivíduos que possuam o conhecimento; financiar pesquisa universitária ou institucional em troca de direto de prioridade no uso comercial de resultados promissores; contratar consultores; (ii) Recursos dirigidos: formar unidades ou grupos para gerar conhecimento (Pesquisa \& Desenvolvimento); (iii) Fusão: reunir pessoas com diferentes perspectivas para trabalhar num problema ou projeto, obrigando-as a chegar a uma resposta conjunta; (iv) Adaptação: adaptar-se constantemente às mudanças ambientais e à competitividade; ( $v$ ) Rede de Conhecimento: manter redes formais e informais de comunicação.

Assim, universidades corporativas podem se tornar viabilizadoras da geração e uso do conhecimento produzido no processo de aprendizagem. O uso do conhecimento, aliado às habilidades e atitudes dos indivíduos expressam as competências desenvolvidas neste processo. Consequentemente, a integração das competências individuais às competências organizacionais, resulta na expressão do que a organização sabe fazer, criando junto aos clientes ou usuários uma identidade organizacional. A partir daí tem-se um conhecimento próprio, desenvolvido pela organização, que é desejável que resulte em ações de gestão do conhecimento.

\subsubsection{Gestão por competências}

A adoção de universidade corporativa pressupõe também a adoção de um modelo de gestão por competências. Conforme Brandão e Guimarães (2001), a gestão por competências propõe-se a orientar esforços para planejar, captar, desenvolver e avaliar, nos diferentes níveis da organização (individual e organizacional), as competências necessárias à consecução de seus objetivos. $O$ diagrama disposto na Figura 1 apresenta as principais etapas ou fases desse processo.

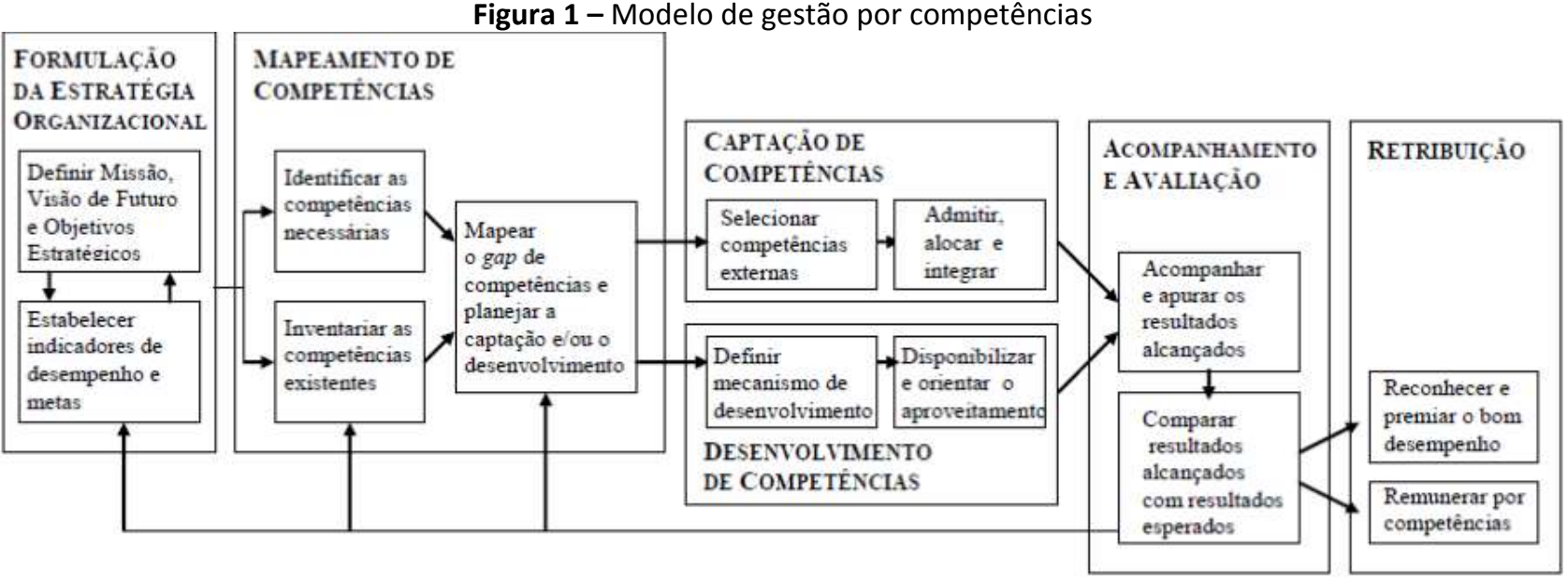

Fonte: Brandão e Bahry (2005) 
Na fase de Formulação da Estratégia Organizacional são definidos sua missão, sua visão de futuro e seus objetivos estratégicos e, então, são também definidos, indicadores de desempenho e metas, com base nos objetivos estratégicos estabelecidos. Uma vez formulada a estratégia organizacional, torna-se possível realizar o mapeamento de competências (BRANDÃO et al., 2005).

No Mapeamento de Competências identifica-se a lacuna de competências, isto é, a diferença entre as competências necessárias para concretizar a estratégia formulada e as competências internas já disponíveis na organização.

A Captação de Competências ocorre, no nível individual, por intermédio de ações de recrutamento e seleção de pessoas e, no nível organizacional, por meio de parcerias ou alianças estratégicas. Essa fase se caracteriza pela seleção de competências externas e sua integração ao ambiente organizacional (BRANDÃO; GUIMARÃES, 2001).

O Desenvolvimento de Competências refere-se ao aprimoramento das competências internas disponíveis na organização, que ocorre, no nível individual, por meio da aprendizagem e, no nível organizacional, por intermédio de investimentos em pesquisa (BRANDÃO; GUIMARÃES, 2001).

A aprendizagem, portanto, é o meio pelo qual são desenvolvidas as competências profissionais, enquanto o desempenho da pessoa no trabalho representa uma manifestação da sua competência, ou seja, uma expressão daquilo que a pessoa aprendeu (FREITAS; BRANDÃO, 2005).

O interesse do presente estudo repousa nessa fase, considerando que os incentivos oferecidos pelo Banco do Brasil para a participação de funcionários em cursos de mestrado e doutorado se constituem de investimento em pesquisa por parte da empresa, bem como proporcionam a aprendizagem do fazer científico. Durante o Acompanhamento e Avaliação são monitorados a execução de planos operacionais e de gestão e os respectivos indicadores de desempenho, visando identificar e corrigir eventuais desvios. Ao final do ciclo, são apurados os resultados alcançados e comparados com os que eram esperados. Na Retribuição, a organização pode reconhecer, premiar e remunerar, de forma diferenciada, as pessoas, equipes de trabalho e unidades produtivas que mais contribuíram para a consecução dos resultados planejados, o que serviria de estímulo à manutenção de comportamentos desejados e à correção de eventuais desvios (BRANDÃO; BAHRY, 2005).

Cabe destacar, no entanto, que a gestão por competências trata-se de um processo contínuo, isso porque a complexidade do ambiente no qual as organizações estão inseridas faz com que sejam exigidos ajustes em sua estratégia e, cada vez mais, novas competências.

\subsubsection{Gestão do conhecimento}

A articulação entre educação corporativa, gestão por competências e gestão do conhecimento pode ser percebida na medida em que a educação corporativa identifica e oferece os meios necessários para o desenvolvimento de competências, permitindo que os profissionais mantenham-se em prontidão para responder às mudanças do ambiente, enquanto a gestão do conhecimento, além de fomentar a geração do conhecimento, também visa o armazenamento, o compartilhamento e a aplicação do conhecimento em um determinado espaço organizacional, utilizando para isso um conjunto de estratégias de ação a fim de lidar com o crescente arsenal de conhecimento na organização.

Os estudos sobre Gestão do Conhecimento despontaram na década de 90, motivados pelo fato de que as empresas tinham perdido muito do conhecimento organizacional após a implementação de processos de reengenharia, downsizing e terceirização (DUARTE; PAIVA; SILVA, 2007). Além disso, as empresas se depararam com contínuas mudanças tecnológicas, 
competidores mais eficientes, clientes mais exigentes, novas responsabilidades sociais e ambientais, entre outros (PAIVA; ARAGÃO; PEREIRA, 2005). Diante dessa nova sociedade, as organizações passam a adotar modelos de gestão do conhecimento para apoiar os processos de conhecimento e obter resultados corporativos favoráveis.

Segundo Paiva e Ferreira (2008), é premissa central da Gestão do Conhecimento "enfatizar o aproveitamento dos recursos intelectuais já existentes nas organizações, de modo que os colaboradores busquem, encontrem e empreguem o conhecimento, as experiências bem sucedidas e as melhores práticas". Embora alguns autores acreditem que isso é apropriação da inteligência dos indivíduos, Duarte, Paiva e Silva (2007) esclarecem que o conhecimento organizacional é resultado do conjunto de conhecimentos individuais, presentes na organização, isto é, o conhecimento organizacional emerge pela interação dos indivíduos.

Nonaka e Takeuchi (1997) reforçam o pressuposto de que o conhecimento (organizacional) é criado por meio da interação do conhecimento tácito com o conhecimento explícito dos indivíduos. Essa interação se dá por quatro modos diferentes de conversão do conhecimento: (i) socialização (do conhecimento tático em conhecimento tácito); (ii) externalização (do conhecimento tácito em conhecimento explícito); (iii) combinação (do conhecimento explícito em conhecimento explícito) e (iv) internalização (do conhecimento explícito em conhecimento tácito).

Para possibilitar essas interações e, consequentemente, a criação do conhecimento, é necessário que se tenha um ambiente favorável. Krogh, Ichijo e Nonaka (2001) denominam essas condições de "capacitadores do conhecimento" e as classificam em cinco ações gerenciais: (i) instalar a visão do conhecimento; (ii) gerenciar conversas; (iii) mobilizar os ativistas do conhecimento; (iv) criar o contexto adequado e (v) globalizar o conhecimento local. Dessa forma, monitorar e gerenciar a informação e o conhecimento é uma tarefa primordial para todas as organizações contemporâneas. Esse aspecto encontra-se presente nos modelos conceituais de gestão do conhecimento estudados por Paiva e Ferreira (2008) que, dentre as contribuições teóricas que subsidiam a construção desses modelos, destacam Davenport e Prusak (1998), Nonaka e Takeuchi (1997), Stewart (1998), Sveiby (1998) e Edvinsson e Malone (1998).

No modelo conceitual de Gestão de Conhecimento de Terra (2001) são identificadas sete dimensões da prática gerencial que compõem a gestão do conhecimento, organizadas segundo o esquema mostrado na Figura 2: (i) fatores estratégicos e o papel da alta administração; (ii) cultura e valores organizacionais; (iii) estrutura organizacional; (iv) administração de recursos humanos; (v) sistemas de informação; (vi) mensuração de resultados e (vii) aprendizado com o ambiente. Essas dimensões, segundo Terra (2001), devem estar presentes nas práticas gerenciais voltadas para a GC, isto é, nas ações organizacionais que visem promover a geração, o compartilhamento e a aplicação do conhecimento. $O$ modelo de GC de Terra (2001) é detalhado no Quadro 1.

Quanto à gestão do conhecimento no Banco do Brasil, organização objeto do presente estudo, Costa, Leite e Carbone (2003) descrevem três iniciativas: (i) Trilhas de Aprendizagem, (ii) TAO - Talentos e Oportunidades e (iii) PGE - Programa Gestão pela Excelência. O primeiro programa tem por objetivo apoiar os funcionários do Banco em seus percursos de profissionalização, orientando-os sobre modalidades de aprendizagem no contexto do trabalho. O TAO é um grande sistema de informações sobre a base de competências pessoais dos funcionários, seus conhecimentos, sua formação escolar, trajeto profissional e desempenho no trabalho. Os autores destacam a iniciativa do PGE, que inspirou-se nas "conversas de cafezinho", momento em que os funcionários compartilham dúvidas, insatisfações e boas ideias, que geralmente se transformam em soluções para os problemas do dia-a-dia. O objetivo do PGE é identificar e compartilhar as melhores práticas de gestão da empresa através de oficinas de debate face a face e por meio do próprio site da Universidade

Perspectivas em Gestão \& Conhecimento, João Pessoa, v. 8, n. 1, p. 155-190, jan./abr. 2018. 
Corporativa Banco do Brasil - UniBB (COSTA; LEITE; CARBONE, 2003).

Figura 2 - Modelo de 7 Dimensões da Gestão do Conhecimento

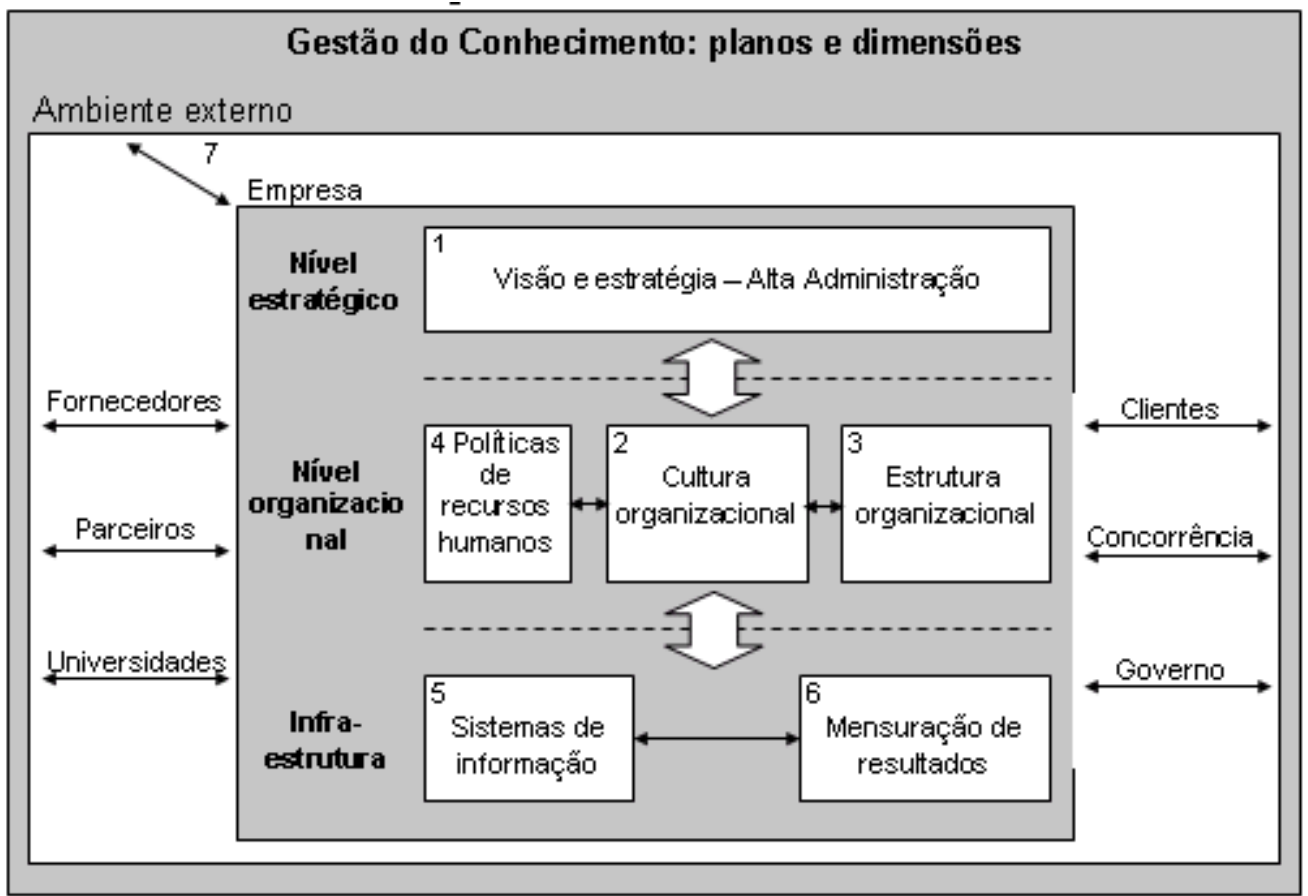

Fonte: Terra (2001, p. 83)

Quadro 1 - Detalhamento do Modelo de 7 Dimensões da Gestão do Conhecimento de Terra (2001)

\begin{tabular}{|l|l|l|}
\hline \multicolumn{1}{|c|}{ Dimensões } & \multicolumn{1}{|c|}{ Descrição } & \multicolumn{1}{c|}{ Detalhamento } \\
\hline $\begin{array}{l}\text { (1) Visão e } \\
\text { adtratégia - alta }\end{array}$ & $\begin{array}{l}\text { Referem-se ao papel da } \\
\text { administração superior na } \\
\text { definição dos campos de } \\
\text { conhecimento, nos quais seus } \\
\text { colaboradores devem focalizar } \\
\text { seus esforços de aprendizado. }\end{array}$ & $\begin{array}{l}\text { Cabe aos gestores do nível estratégico a } \\
\text { identificação e o desenvolvimento das } \\
\text { principais competências necessárias para a } \\
\text { operacionalização da estratégia corporativa, } \\
\text { pois, sem o envolvimento das lideranças } \\
\text { institucionais a eficácia da GC pode ser } \\
\text { prejudicada. }\end{array}$ \\
\hline $\begin{array}{l}\text { (2) Cultura } \\
\text { organizacional }\end{array}$ & $\begin{array}{l}\text { Referem-se ao desenvolvimento } \\
\text { de uma cultura organizacional } \\
\text { voltada para a inovação, a } \\
\text { experimentação e o aprendizado } \\
\text { contínuo e comprometido com } \\
\text { os resultados de longo prazo e } \\
\text { com a otimização de todas as } \\
\text { áreas da organização. }\end{array}$ & $\begin{array}{l}\text { Por cultura entende-se as "normas e valores } \\
\text { que ajudam a interpretar eventos e avaliar o } \\
\text { que é apropriado e inapropriado". Uma cultura } \\
\text { organizacional baseada na inovação e no } \\
\text { aprendizado deve ser valorizada, uma vez que } \\
\text { cria um contexto favorável à geração e ao } \\
\text { compartilhamento de conhecimentos. }\end{array}$ \\
\hline $\begin{array}{l}\text { (3) Estrutura } \\
\text { organizacional }\end{array}$ & $\begin{array}{l}\text { arquiteturas organizacionais e às } \\
\text { práticas de organização do } \\
\text { trabalho que diversas } \\
\text { organizações estão adotando } \\
\text { para superar os limites à } \\
\text { inovação, ao aprendizado e à } \\
\text { geração de novos } \\
\text { conhecimentos. }\end{array}$ & $\begin{array}{l}\text { Os modelos puramente } \\
\text { burocráticos/mecanicistas estão se tornando } \\
\text { inadequados para as organizações diante dos } \\
\text { atuais desafios. Assim, tem aumentado o } \\
\text { número de organizações com estrutura em } \\
\text { rede, que favorece o processo de } \\
\text { comunicação, as parcerias e o relacionamento } \\
\text { entre os pares, através de uma estrutura } \\
\text { orgânica. Segundo Terra, várias empresas têm } \\
\text { adotado uma junção dessas duas formas de } \\
\text { estrutura, considerando que a burocrática é a }\end{array}$ \\
\hline
\end{tabular}

Perspectivas em Gestão \& Conhecimento, João Pessoa, v. 8, n. 1, p. 155-190, jan./abr. 2018. 


\begin{tabular}{|c|c|c|}
\hline Dimensões & Descrição & Detalhamento \\
\hline & & $\begin{array}{l}\text { mais adequada para a acumulação de } \\
\text { conhecimentos, e a orgânica é mais adequada } \\
\text { para a geração de conhecimentos. }\end{array}$ \\
\hline $\begin{array}{l}\text { (4) Políticas de } \\
\text { recursos } \\
\text { humanos }\end{array}$ & $\begin{array}{l}\text { Menciona as políticas } \\
\text { organizacionais, associadas ao } \\
\text { conhecimento, ao aprendizado e } \\
\text { à criatividade. }\end{array}$ & $\begin{array}{l}\text { Os colaboradores estão bastante interessados } \\
\text { no desenvolvimento pessoas, e as empresas } \\
\text { almejam que eles contribuam continuamente } \\
\text { com o conhecimento organizacional. Nessa } \\
\text { dimensão, destacam-se os seguintes processos: } \\
\text { recrutamento e seleção, treinamento e carreira } \\
\text { e sistema de recompensa. O recrutamento e } \\
\text { seleção são vistos como investimentos, posto } \\
\text { que visam contratar pessoas com } \\
\text { competências cognitivas e sociais que atendam } \\
\text { às demandas da organização. O treinamento } \\
\text { deve ser percebido como um processo de } \\
\text { aprendizado contínuo. O sistema de carreira e } \\
\text { recompensa deve estar atrelado às políticas de } \\
\text { aprendizado organizacional, possibilitando a } \\
\text { rotatividade de funções/papéis e estimulando } \\
\text { o desempenho da equipe. }\end{array}$ \\
\hline $\begin{array}{l}\text { (5) Sistemas de } \\
\text { informação }\end{array}$ & $\begin{array}{l}\text { Referem-se aos avanços na } \\
\text { informática e na tecnologia de } \\
\text { comunicação, que estão } \\
\text { afetando os processos de gestão } \\
\text { do conhecimento nas } \\
\text { organizações. }\end{array}$ & $\begin{array}{l}\text { Normalmente, a "associação entre tecnologia } \\
\text { de informação e gestão do conhecimento está } \\
\text { relacionada ao uso de sistemas de informação } \\
\text { para o compartilhamento de informações ou } \\
\text { conhecimento". Contudo, os investimentos em } \\
\text { tecnologia da informação não geram, } \\
\text { necessariamente, melhores desempenhos } \\
\text { corporativos, pois "conhecimento é } \\
\text { informação interpretada, o que faz com que a } \\
\text { simples transferência de informação não } \\
\text { aumente o conhecimento ou a competência". }\end{array}$ \\
\hline $\begin{array}{l}\text { (6) Mensuração } \\
\text { de resultados }\end{array}$ & $\begin{array}{l}\text { Diz respeito ao esforço } \\
\text { organizacional em avaliar os } \\
\text { ativos baseados em } \\
\text { conhecimento. }\end{array}$ & $\begin{array}{l}\text { Terra acredita que se as organizações se } \\
\text { envolvem em processos de contabilização do } \\
\text { capital intelectual, poderão conhecer melhor } \\
\text { seus processos, sua cultura, suas estratégias e } \\
\text { suas políticas, levando-as a desenvolverem } \\
\text { práticas mais sintonizadas com o aprendizado, } \\
\text { a inovação e a geração de conhecimentos. }\end{array}$ \\
\hline $\begin{array}{l}\text { (7) Aprendizado } \\
\text { com o } \\
\text { ambiente }\end{array}$ & $\begin{array}{l}\text { Reporta-se à crescente } \\
\text { necessidade de as organizações } \\
\text { se engajarem em processos de } \\
\text { aprendizado com o ambiente, } \\
\text { em particular, por meio de } \\
\text { alianças e parcerias com as } \\
\text { outras organizações e os } \\
\text { clientes. }\end{array}$ & $\begin{array}{l}\text { A questão do aprendizado com o ambiente } \\
\text { relaciona-se diretamente com as demais } \\
\text { dimensões do modelo de GC e proporciona a } \\
\text { exploração de novas perspectivas para o } \\
\text { avanço do conhecimento. }\end{array}$ \\
\hline
\end{tabular}

Fonte: Paiva e Ferreira (2008), com adaptações.

No entanto, para que haja o aprendizado com o ambiente, a empresa não deve ficar restrita aos seus limites físicos. Pelo contrário, é a partir da interação da organização com o ambiente externo que as informações são absorvidas, processadas e transformadas em conhecimento (DAVENPORT; PRUSAK, 1998).

Como um dos focos da gestão do conhecimento é a criação do conhecimento, muitas 
vezes é necessário que a organização procure aonde existe ou pode ser produzido determinado conhecimento que lhe é útil. Assim, as universidades, geradoras de conhecimento por excelência, se tornam um local apropriado para se buscar ou produzir o conhecimento. Desta forma, as organizações passam a incentivar a formação em nível superior de seus funcionários, inclusive em cursos de mestrado e doutorado. Este tipo de iniciativa de gestão do conhecimento também está presente no Banco do Brasil, por meio do Programa UniBB de mestrado e doutorado.

\subsubsection{Conceitos de transferência e de impacto de treinamento}

Segundo Latham (1989), transferência de aprendizagem pode ser definida como o grau em que os treinandos aplicam, em seus trabalhos, conhecimentos, habilidades, comportamentos e atitudes adquiridas em treinamento. Isso significa dizer que as pessoas aprendem um conjunto de CHAs e transferem essa aprendizagem para uso em outro contexto.

Já o conceito de impacto de treinamento é quando há produção de mudanças observáveis no desempenho do indivíduo treinado (FREITAS, 2005). A aplicação dos CHAs aprendidos é uma condição essencial para que haja mudanças. Todavia, embora possa haver transferência de aprendizagem, o impacto pode não ser significativo. Podem ser identificados dois tipos de impacto, segundo Freitas (2005):

- impacto em profundidade representa as melhorias no desempenho em tarefas diretamente relacionadas aos objetivos e conteúdos ensinados no treinamento; e

- impacto em amplitude ou em largura refere-se às melhorias no desempenho geral, em tarefas não diretamente relacionadas aos conteúdos ensinados no treinamento.

Freitas (2005) faz uma revisão de literatura quanto às teorias que dão suporte à transferência de treinamento e categoriza os preditores de treinamento. $O$ suporte à transferência - também denominado clima para transferência - representa, segundo Freitas (2005), "uma medida perceptual das condições encontradas no local de trabalho, facilitadoras ou restritoras do uso dos novos conhecimentos, habilidades e atitudes aprendidos pela pessoa". Representa uma condição básica para que ocorra a aplicação, no trabalho, daquilo que foi aprendido pelo indivíduo.

Segundo Yamnill e McLean (2001), muitas teorias de comportamento humano ajudam a compreender e predizer comportamentos que contribuem para o desempenho no trabalho, bem como para transferência de aprendizagem.

Em relação aos preditores de impacto de treinamento no cargo, Freitas (2005) indica que a literatura científica nacional e internacional classifica os preditores de impacto de treinamento em profundidade e em largura em três categorias: (i) características individuais, atributos do participante da ação educacional, tais como idade, escolaridade, motivação para aprender, nível de aprendizagem, cargo ocupado, tempo de empresa, (ii) características do treinamento, atributos específicos da ação educacional, tais como tipo de treinamento (cognitivo, psicomotor), técnicas didáticas, quantidade de educadores, e (iii) características do contexto, atributos do local de trabalho, tais como suporte material, suporte psicossocial, valorização do funcionário, tipo de tarefa.

Freitas (2005) analisou 20 trabalhos nacionais, dois quais 12 avaliaram o impacto do treinamento apenas em largura e oito adotaram as duas medidas (profundidade e largura). Foi constatada a ocorrência de similaridades entre os preditores de impacto de treinamento em profundidade e em largura, considerando cada uma das categorias pesquisadas. Os resultados apresentados por Freitas (2005) foram os seguintes:

Perspectivas em Gestão \& Conhecimento, João Pessoa, v. 8, n. 1, p. 155-190, jan./abr. 2018. 
No que se refere às características individuais, os preditores mais frequentes foram motivação para treinamento e escolaridade, presentes em $14 \%$ das pesquisas (3). O local ou unidade de trabalho foi preditor em duas pesquisas (10\%). As demais variáveis apareceram em apenas um estudo.

O preditor mais frequente da categoria características do treinamento foi o tipo de treinamento (cognitivo, afetivo ou psicomotor), presente em 19\% das pesquisas (4). Suporte à transferência foi a variável de contexto mais pesquisada.

Suporte psicossocial atuou como preditor em $81 \%$ das pesquisas (17) e o suporte material, em $24 \%$ delas (5). A explicação do suporte psicossocial foi responsável por $20 \%$ a $54 \%$ da variância de impacto de treinamento no desempenho

O suporte psicossocial destaca-se em vários estudos como o principal preditor do impacto de treinamento no desempenho do indivíduo. Essa variável aborda o apoio dado pelos chefes e colegas à aplicação, no trabalho, dos CHAS aprendidos em treinamento.

O suporte à transferência, como principal variável preditora de impacto no nível do indivíduo, reforça a importância das variáveis de contexto na explicação do impacto de treinamento. Essas variáveis podem estar mais próximas do indivíduo treinado, como é o caso do suporte à transferência ou podem estar mais distantes, representando as políticas, 0 sistema de treinamento e o clima vigente na organização (FREITAS, 2005).

O suporte à transferência representa uma medida perceptual das condições encontradas no local de trabalho, facilitadoras ou restritoras do uso dos novos CHAs na execução das tarefas. Nesse sentido, segundo Freitas (2005), suporte à transferência é uma medida da percepção sobre um contexto restrito, aquele que representa as condições necessárias à aplicação dos novos conteúdos aprendidos. Este tema tem sido altamente pesquisado na literatura (FREITAS, 2005). Assim, essa variável tem lugar de destaque no desenho desta pesquisa, tendo em vista seu valor preditivo.

\subsection{Conhecimento científico}

Etimologicamente, ciência significa conhecimento. Mas, nem todos os tipos de conhecimento pertencem à ciência. Segundo Marconi e Lakatos (2011), o que diferencia o conhecimento vulgar ou popular, às vezes denominado senso comum, do conhecimento científico é a forma, o modo ou o método e os instrumentos do "conhecer". Não é pela veracidade nem pela natureza do objeto conhecido que eles se diferenciam. Segundo essas autoras, a ciência não é o único caminho de acesso ao conhecimento e à verdade. Até porque

[...] um mesmo objeto ou fenômeno - uma planta, um mineral, uma comunidade ou as relações entre chefes e subordinados - pode ser matéria de observação tanto para o cientista quanto para o homem comum; o que leva um ao conhecimento científico e outro ao vulgar ou popular é a forma de observação. (MARCONI E LAKATOS, 2011, p. 76).

Assim, o conhecimento científico diferencia-se do popular muito mais no que se refere ao seu contexto metodológico do que propriamente ao seu conteúdo. Essa diferença ocorre também em relação aos conhecimentos filosófico e religioso (teológico).

Segundo Marconi e Lakatos (2003, p. 79), o conhecimento científico "abrange fatos concretos, positivos, e fenômenos perceptíveis pelos sentidos, através do emprego de instrumentos, técnicas e recursos de observação". Ainda para essas autoras, "o fundamento do conhecimento científico consiste na evidência dos fatos observados e experimentalmente controlados" (MARCONI; LAKATOS, 2003, p. 79). 


\subsection{Conhecimento Científico Explícito e Conhecimento Científico Tácito}

A ciência tem o papel de promover o desenvolvimento da sociedade, o que logicamente inclui as empresas que podem usufruir do conhecimento científico criado. A criação do conhecimento científico ocorre essencialmente por meio de pesquisas científicas realizadas por pesquisadores (LEITE; COSTA, 2006), que usam métodos e instrumentos reconhecidamente válidos.

Segundo Leite (2006), além do conhecimento científico explícito, validado por membros da comunidade acadêmica e explicitado por meio de publicações, existe um conhecimento científico que não pode ser explicitado, que consiste no conhecimento científico tácito. Esse conhecimento científico tácito, segundo o autor, faz parte da estrutura cognitiva do pesquisador, dotado de flexibilidade, desarticulado e subjetivo, e que somente em parte pode ser comunicado. Assim, Miranda (2004) define o conhecimento científico como:

[...] o conjunto de saberes baseados na experiência, proveniente das atividades de pesquisa, e na informação científica, natural do ambiente acadêmico, contextual e relacional, composto de duas vertentes: a tácita, própria do indivíduo, proveniente da experiência, relacionada às habilidades e competências, parte de sua estrutura cognitiva, portanto, subjetiva: e a explícita (ou codificada), externa ao indivíduo (informação) proveniente da externalização do conhecimento tácito. (MIRANDA, 2004, p. 12)

O conhecimento científico tácito, por sua vez, segundo Leite e Costa (2006), refere-se ao conhecimento ou habilidade que pode ser passada entre cientistas por contatos pessoais, porém, não pode ser exposto ou passado por diagramas, fórmulas, descrições verbais ou instruções para ação. Este conhecimento, relacionado com a experiência e competência do pesquisador e baseado na informação científica é, porém, de difícil sistematização e representação (LEITE; COSTA, 2006).

Embora o conhecimento tácito seja aceito no contexto das organizações empresariais, falar em conhecimento científico tácito pode soar estranho a priori, como observa Leite (2006, p. 48). Isto porque para se considerar um conhecimento como científico, este deve atingir patamares de controlabilidade e credibilidade alcançados por métodos científicos, conforme os princípios que regem o que é e o que não é ciência. No entanto, segundo o autor (LEITE, 2006, p. 51), o conhecimento "relacionado às habilidades, experiências e competências de um pesquisador, empregado no desenvolvimento de suas atividades científicas e difícil de ser comunicado formalmente" é conhecimento científico tácito. Leite (2006) mostra a presença do conhecimento científico tácito na produção do conhecimento científico.

A noção de conhecimento científico tácito se torna relevante para este estudo na medida que faz parte da estrutura cognitiva do pesquisador, podendo, assim, ser aplicado em ambientes diferentes do que o acadêmico. Neste estudo, o conjunto dos conhecimentos científicos explícitos e tácitos é chamado de competências científicas.

\subsection{Competências científicas}

Segundo Velho (2007), as instituições de ensino superior produzem resultados de pesquisa que podem ser diretamente apropriados pelas empresas no seu processo de inovação. Em meio a todos os benefícios que o sistema de educação superior pode gerar para o processo de inovação - seja para o setor produtivo, seja para a sociedade como um todo - a formação de recursos humanos parece ser o mais importante, uma vez que as universidades produzem profissionais e pesquisadores qualificados. Estes, ao serem incorporados pelas 
empresas e outros setores da sociedade, levam consigo não apenas conhecimento científico recente, mas também habilidades para resolver problemas complexos, realizar pesquisa e desenvolver novas ideias.

Leite (2006, p. 67) defende que o conhecimento científico pode ser compartilhado tanto formal como informalmente, de forma explícita ou tácita. Os mestres e doutores possuem também habilidade tácita para adquirir e usar conhecimento de maneira inovadora, além de deter o que alguns autores chamam de "conhecimento do conhecimento", ou seja, sabem quem sabe o que, pois participam das redes acadêmicas e profissionais no nível nacional e internacional. Quando os mestres e doutores se engajam em atividades fora do meio acadêmico, os produtos resultantes dessas interações nem sempre se resumem a publicações. Esses pesquisadores tendem a imprimir em tais contextos uma nova atitude mental e espírito crítico que favorecem as atividades "inovativas" (VELHO, 2007).

Assim, mesmo que a dissertação ou tese desenvolvida seja integralmente implementada, o retorno do investimento na formação profissional realizado pela empresa, bem como o efeito das competências desenvolvidas na universidade não se esgotam nessa aplicação no ambiente empresarial, mas permanecem presentes, pois seus autores permanecem atuando nesse ambiente em outras atividades e projetos.

O tema competências científicas desenvolvidas pelos mestres e doutores foi tratado por Pilati, Porto e Silvino (2007). Esses autores identificaram as competências genéricas que programas de mestrado e doutorado nas diversas áreas do conhecimento almejam desenvolver em seus alunos. Isso ocorreu, segundo os autores, devido à impossibilidade de se associar competências específicas a programas de mestrado e doutorado, uma vez que, geralmente, egressos de programas organizacionais dessa natureza realizam seus cursos em diferentes áreas do conhecimento. Como resultado desse estudo, eles identificaram 18 competências científicas, que serão melhor detalhadas na seção método desse artigo, uma vez que o instrumento de Pilati, Porto e Silvino (2007) foi adotado nesta pesquisa.

\subsection{Aplicação das competências científicas no trabalho}

Davenport e Prusak (2005, p. 65) relatam que em 1995, quando a IBM comprou a Lotus e pagou U\$\$ 3,5 bilhões, quatorze vezes a avaliação contábil de US\$ 250 milhões, ela não estava adquirindo simplesmente uma nova empresa, nem por causa da quantia da receita gerada por seus produtos, como o Notes, ou pela sua capacidade industrial ou de vendas, mas pelo conhecimento exclusivo sobre aplicativos de uso colaborativo. Os funcionários da Lotus desenvolveram competências técnicas que, a certo momento, transcenderam a organização e o produto por eles desenvolvido. Este novo conhecimento seria acrescentado pela IBM ao seu próprio estoque.

Assim, o uso das competências científicas adquiridas durante cursos stricto sensu não se limitam ao desenvolvimento da dissertação ou tese ou estão restritas ao ambiente acadêmico. Elas podem ser aplicadas às diversas situações e organizações em que os mestres e doutores atuarem, considerando que se tornaram intrínsecas ao indivíduo.

Bahry e Tolfo (2007) desenvolveram estudo no Banco do Brasil sobre a mobilização de competências nas atividades profissionais dos egressos do programa de pós-graduação stricto sensu daquela instituição. $O$ estudo demonstrou que os egressos desenvolveram diversos conhecimentos, habilidades e atitudes (competências) ao longo do curso.

Pilati, Porto e Silvino (2007) desenvolveram um instrumento de pesquisa para mensurar quais competências científicas são desenvolvidas em cursos de mestrado e doutorado. Além de identificarem essas competências, também investigaram a aplicação dessas no ambiente organizacional. Para isso, verificaram o domínio e frequência de uso das competências científicas no trabalho. Isso se deu no âmbito da psicologia, sob a ótica de

Perspectivas em Gestão \& Conhecimento, João Pessoa, v. 8, n. 1, p. 155-190, jan./abr. 2018. 
avaliação de ações de treinamento, desenvolvimento e educação em organizações (TD\&E). A partir do enfoque de transferência de aprendizagem para o trabalho, desenvolveram um instrumento que busca aferir essa transferência, a retenção das competências desenvolvidas na capacitação e o efeito da capacitação no desempenho e na motivação do egresso. A pesquisa foi aplicada em uma organização pública brasileira com seu programa de pósgraduação stricto sensu implantado e regulamentado há mais de 13 anos, e esse programa já formou 389 funcionários em nível de mestrado e 39 em nível de doutorado.

Os resultados indicaram que havia um excelente grau de validade de construto, o que corrobora a ideia de que a formação em nível de pós-graduação possui um conjunto de competências centrais almejadas como foco da formação de mestres e doutores. A validação psicométrica indicou que as duas facetas perceptuais são validamente mensuradas pelas subescalas (frequência e domínio). Os egressos perceberam maior retenção das competências do que relataram, em relação à frequência de uso no ambiente laboral, em decorrência da demanda, não muito elevada, de uso das competências no trabalho, o que deve estar relacionado às condições situacionais da organização como determinantes do uso das competências.

As condições situacionais do ambiente organizacional, que segundo Pilati, Porto e Silvino (2007) são determinantes para o uso das competências, podem ser denominadas como suporte à transferência da aprendizagem. Pilati, Porto e Silvino (2007) destacam, entretanto, que estudos que busquem aferir o efeito de programas de pós-graduação são raros na literatura brasileira e internacional, e ressaltam a necessidade de que suas escalas sejam aplicadas em contextos organizacionais diferenciados, visando à aferição de transferência de aprendizagem e de impacto no trabalho de programas de mestrado e doutorado de outras organizações. No presente trabalho, ao se utilizar tal instrumento no Banco do Brasil, busca-se seguir a recomendação dos autores.

Bahry, Brandão e Freitas (2008) avaliaram "os impactos do suporte à transferência sobre a aplicação de competências no trabalho dos mestres e doutores do Banco do Brasil". Foi observado que os respondentes aplicam no trabalho, com razoável frequência ( $m=7,05$, em uma escala até 10), as competências que desenvolveram em seus cursos. No entanto, o desvio-padrão indicou que essa percepção não é homogênea, alguns aplicam muito e outros não. Com referência ao suporte à aplicação dessas competências, em geral, os respondentes se sentem seguros e motivados para aplicar, no trabalho, suas competências. Obtiveram menores médias, por outro lado: (i) os itens referentes a estímulos do gerente, (ii) o que trata de suporte material e (iii) o que diz respeito a consequências do uso da aprendizagem. Essa última variável, no entanto, segundo Brandão, Bahry e Freitas (2008), pode ser entendida de forma invertida, ou seja, quanto menor a sua média, melhor a percepção sobre o suporte oferecido pela empresa, uma vez que a censura ou a punição às falhas do funcionário pode inibir futuras tentativas de aplicação das competências desenvolvidas, enquanto a tolerância ao erro geralmente constitui um fator de estímulo à transferência da aprendizagem.

Verificou-se, no entanto, que a percepção dos funcionários acerca do suporte oferecido pela empresa é moderadamente positiva $(m=6,74$ para o suporte psicossocial e $m=$ 6,13 para o suporte material, em uma escala até 10), indicando ser possível aprimorar o apoio disponibilizado à transferência da aprendizagem, o que traria reflexos mais positivos sobre a expressão de competências no trabalho.

Esses autores verificaram a existência de relação preditiva entre a percepção dos mestres e doutores acerca do suporte à transferência da aprendizagem oferecido pela organização e a aplicação, no trabalho, de competências por eles desenvolvidas em cursos de pós-graduação stricto sensu. Diante de tal resultado, o Banco poderia melhorar os níveis de aplicação das competências se investir no aperfeiçoamento do suporte à transferência. A pesquisa de Brandão, Bahry e Freitas foi aplicada no Banco do Brasil em 2005.

Perspectivas em Gestão \& Conhecimento, João Pessoa, v. 8, n. 1, p. 155-190, jan./abr. 2018. 
Cabe destacar que Brandão, Bahry e Freitas (2008) não identificam quais competências são desenvolvidas em cursos de mestrado e doutorado, apenas avaliaram a frequência de aplicação das competências desenvolvidas a partir de uma pergunta genérica: "Aplico no meu trabalho, as competências desenvolvidas no curso de mestrado e/ou doutorado que realizei". Todavia, a contribuição de sua pesquisa é relevante para o presente estudo por indicar a importancia do suporte à transferência para a aplicação das aprendizagens.

Passados oito anos da pesquisa realizada por Brandão, Bahry e Freitas e seis anos da publicação da pesquisa de Pilati, Porto e Silvino, permanecem raros estudos que tratem sobre a aplicação competências científicas no ambiente das organizações.

Considerando que este estudo adota os instrumentos desenvolvidos por Pilati, Porto e Silvino (2007) e por Bahry, Brandão e Freitas (2008), consolidando-os em um novo instrumento, os instrumentos serão mais detalhados na seção método.

Considerando que o reconhecimento pelos gerentes de que a geração de conhecimento é ao mesmo tempo uma atividade importante para o sucesso corporativo e um processo que pode ser alimentado (DAVENPORT; PRUSAK, 2003), este estudo aplica os instrumentos desenvolvidos por Brandão, Bahry e Freitas (2008) - excetuando-se as questões abertas do instrumento - e por Pilati, Porto e Silvino (2007), porém de forma congregada, gerando um novo instrumento de pesquisa. Tal instrumento é composto por competências científicas e da percepção de suporte à aplicação dessas competências no ambiente organizacional.

\subsection{Gestão do conhecimento científico}

Para que se tenha uma melhor compreensão de como são desenvolvidas as competências científicas em estudantes de cursos de pós-graduação stricto sensu, é interessante conhecer o processo de gestão do conhecimento científico.

As universidades, tradicionalmente, têm sido reconhecidas como espaços de produção e transferência de conhecimento científico por excelência (LEITE; COSTA, 2006). Desta forma, o ambiente acadêmico torna-se apropriado ao olhar da Gestão do Conhecimento. No entanto, é preciso considerar as peculiaridades da natureza do conhecimento científico, bem como do ambiente onde ele é criado, compartilhado e usado. Desta forma, o conhecimento científico não está desconectado do contexto acadêmico em que está sendo produzido (MACIASCHAPULA, 1998).

Buscando aplicar a Gestão do Conhecimento no contexto universitário, Paiva e Duarte (2006) propõem uma adaptação do modelo de Terra (2001), já mostrado na Figura 2, ancorada em dois pontos: de um lado, consideram-se as semelhanças entre os processos da Gestão do Conhecimento e o sistema de comunicação científica (criação-produção, compartilhamentodisseminação, aplicação-uso) e, de outro, incorpora um conjunto de elementos organizacionais de apoio a esses processos. Esse novo modelo é apresentado na Figura 3. Nesse caso, o modelo de Paiva e Duarte (2006) abrange as seguintes dimensões da prática gerencial: (i) fatores estratégicos e papel da alta administração, (ii) cultura e valores organizacionais, (iii) estrutura organizacional, (iv) administração de recursos humanos, (v) sistemas de informação, (vi) mensuração de resultados e (vii) aprendizado com o ambiente. Assim, além do ambiente empresarial, a Gestão do Conhecimento também pode ser aplicada no ambiente acadêmico, com os processos adaptados por Paiva e Duarte (2006).

A criação de conhecimento pode ser estimulada através da formação de grupos de estudos, da participação em pesquisas e em eventos, da produção científica, entre outros. As autoras enfatizam: para que esse processo ocorra, o ambiente não pode estimular a mera repetição de teorias e conceitos, mas a criatividade e novas ideias devem ser incentivadas através de um ambiente favorável a debates e discussões.

Perspectivas em Gestão \& Conhecimento, João Pessoa, v. 8, n. 1, p. 155-190, jan./abr. 2018. 
O armazenamento de conhecimentos focaliza o conhecimento explícito, ou seja, aquele adquirido através de aulas ou conferências, enquanto o conhecimento tácito - pessoal e difuso - é acumulado com a experiência e a prática, sendo diferenciado em cada indivíduo. Esse processo torna-se essencial na medida que o volume crescente de informações e conhecimentos requer um suporte tecnológico para arquivar, agrupar, selecionar e recuperar elementos informacionais relevantes para o processo educativo e para a vida profissional.

Figura 3 - Gestão do Conhecimento Científico: processos e estratégias

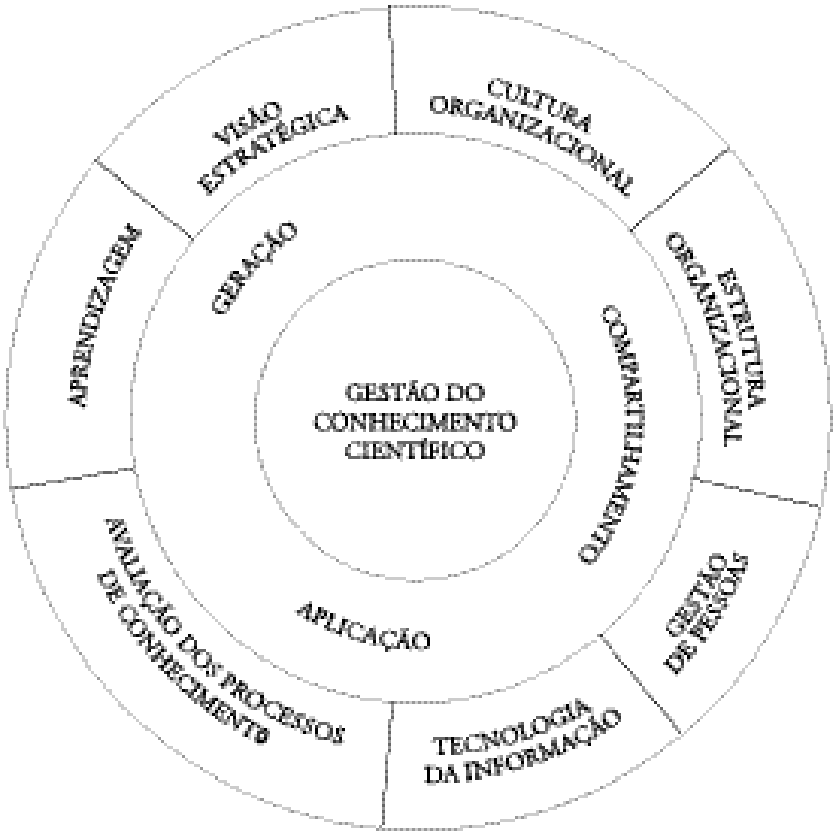

Fonte: Paiva e Duarte (2006)

No contexto acadêmico a disseminação de conhecimentos é uma ação intrínseca ao processo educacional que pode se dar tanto em sala de aula quanto em qualquer outro espaço e a qualquer momento. As autoras destacam ser importante incentivar a comunidade acadêmica (docentes e estudantes) para uma cultura de compartilhamento de conhecimentos, instigando-os a interagir entre si. A transferência de conhecimentos pode ocorrer de modo formalizado (estruturado) ou de modo espontâneo (não estruturado).

A aplicação do conhecimento é essencial, considerando que o conhecimento gerado e compartilhado deve ser utilizado para auxiliar as pessoas, as organizações e a sociedade na compreensão e solução dos problemas. Esse é um dos principais objetivos educativos, no contexto acadêmico.

Leite e Costa (2006) criticam algumas iniciativas de se estudar a gestão do conhecimento no ambiente acadêmico, uma vez que consideram que se resumem a iniciativas de desenvolvimento de tecnologia da informação ou na perspectiva de gestão do conhecimento organizacional. Para os autores, as peculiaridades do conhecimento científico devem ser consideradas, bem como o processo de comunicação, que se torna fundamental para a criação, armazenamento, compartilhamento e aplicação do conhecimento.

De acordo com Leite e Costa (2006):

[Gestão do Conhecimento Científico é] o planejamento e controle de ações (políticas, mecanismos, ferramentas, estratégias e outros) que governam o fluxo do conhecimento científico em sua vertente tácita e explícita, tendo como substratos os processos de comunicação científica com o fim de 
apoiar e maximizar a criação de novos conhecimentos e o ensino.

Leite (2006) propõe o modelo de Gestão do Conhecimento Científico mostrado na Figura 4, desenvolvido a partir do ambiente acadêmico, que contempla a comunicação como processo fundamental. Os processos que compõem esse modelo são descritos no Quadro 2.

Figura 4 - Modelo conceitual de gestão do conhecimento científico no contexto acadêmico

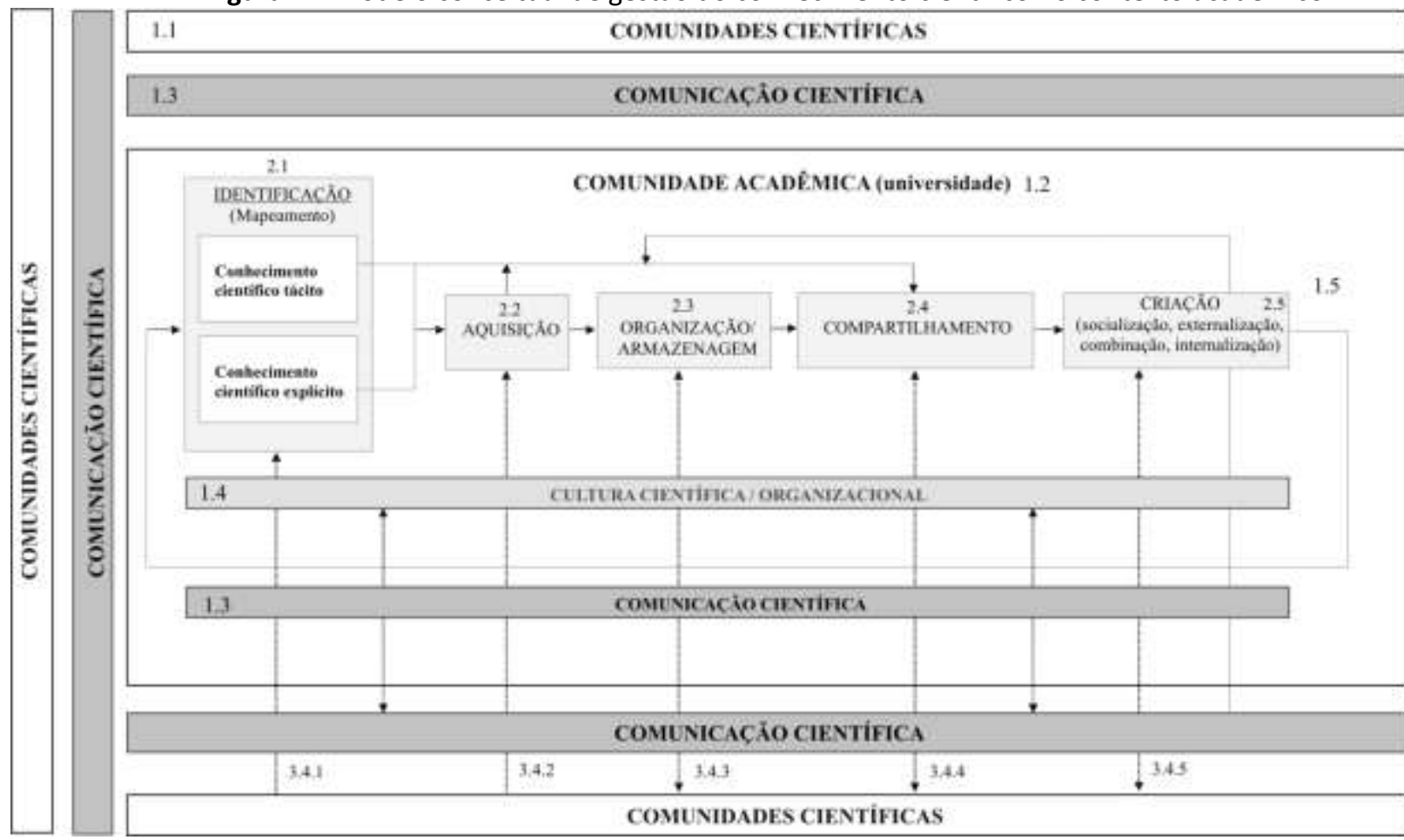

Fonte: Leite (2006, p. 194)

Quadro 2 - Processo da Gestão do Conhecimento Científico

\begin{tabular}{|l|l|}
\hline \multicolumn{1}{|c|}{ Processo } & \multicolumn{1}{c|}{ Descrição } \\
\hline Identificação & $\begin{array}{l}\text { Processo de mapeamento do conhecimento da comunidade acadêmica - } \\
\text { conhecimentos internos à instituição - em sua vertente proveniente de } \\
\text { comunidades científicas. O objetivo é responder quem pesquisa o quê e onde. } \\
\text { Trata-se do mapeamento das fontes de informação e competências científicas } \\
\text { internas e externas da instituição e das fontes de informação e competências } \\
\text { científicas críticas que estejam relacionadas às atividades científicas da instituição. }\end{array}$ \\
\hline Aquisição & $\begin{array}{l}\text { Processo de aquisição dos conhecimentos mapeados anteriormente, necessários à } \\
\text { criação e manutenção de conhecimentos e competências científicas da } \\
\text { comunidade acadêmica. }\end{array}$ \\
\hline $\begin{array}{l}\text { Armazenamento / } \\
\text { Organização }\end{array}$ & $\begin{array}{l}\text { Processo relacionado com a organização e armazenagem do conhecimento } \\
\text { científico explícito com o intuito de torná-lo facilmente recuperável. }\end{array}$ \\
\hline Compartilhamento & $\begin{array}{l}\text { Processo que tem como pressuposto o compartilhamento do conhecimento } \\
\text { científico explícito, pelos meios de comunicação formais e o compartilhamento do } \\
\text { conhecimento tácito, por meios informais. }\end{array}$ \\
\hline Criação & $\begin{array}{l}\text { Processo relacionado com a criação de novas habilidades, competências e } \\
\text { conhecimento na instituição. }\end{array}$ \\
\hline
\end{tabular}

Fonte: Adaptado de LEITE, 2006 por Ferreira (2010)

Leite e Costa (2006) destacam que os processos de gestão do conhecimento científico, no contexto de uma comunidade acadêmica, sofrem influência externa das comunidades 
científicas, como sugerem os resultados. Por esta e outras razões, a identificação, aquisição, organização/armazenagem e, sobretudo, o compartilhamento e criação do conhecimento científico, como processos de gestão do conhecimento no contexto de uma universidade, não podem prescindir ou desprezar a interferência de várias lateralidades, tanto internas quanto externas, de caráter cultural, tecnológico ou social.

O processo de gestão do conhecimento científico tem por objetivo oferecer suporte, potencializar e tornar mais eficientes as atividades de pesquisa e ensino na instituição e a integração entre elas - e, por consequência, o estímulo à criação de novos conhecimentos (LEITE; COSTA, 2006).

Porém, esses novos conhecimentos, por sua vez, não se restringem ao consumo interno das universidades, pelo contrário, devem ser aplicados em benefício da sociedade. Neste contexto, as empresas também podem se beneficiar da aplicação de conhecimentos científicos em seus processos produtivos.

\section{PESQUISA E MÉTODO}

\subsection{A empresa pesquisada}

O Banco do Brasil possui o seu programa de apoio à participação dos funcionários em mestrado e doutorado, implantado e regulamentado há mais de 15 anos, e esse programa apoiou mais de 287 funcionários em cursos de mestrado e doutorado. Atualmente, o Banco dispõe de 1.055 mestres e 59 doutores em seu quadro funcional, dos quais cerca de $20 \%$ (215 funcionários) foram patrocinados por meio do Programa UniBB de Mestrado e Doutorado.

A estratégia utilizada foi o estudo de caso, onde se explorou em profundidade um programa de determinada organização, no caso o Programa UniBB de Mestrado e Doutorado.

\subsection{Participantes da pesquisa}

A população que fez parte do universo da pesquisa foi composta por 172 funcionários em atividade, residentes no Brasil e exterior, que participaram do Programa UniBB de Mestrado e Doutorado no período de 1997 a 2011 (beneficiados com bolsas para cursos de pós-graduação stricto sensu), na modalidade pesquisador (com afastamento parcial do trabalho) e na modalidade bolsista (sem afastamento do trabalho) e já haviam retornado ao trabalho no banco no período em que se iniciou a coleta de dados.

\subsection{Instrumentos de pesquisa}

A coleta de dados foi realizada por meio de pesquisa em documentos da organização e de um questionário, composto de questões fechadas, originárias da junção de dois instrumentos de coleta: um desenvolvido por Pilati, Porto e Silvino (2007) e o outro por Brandão, Bahry e Freitas (2008) - excetuando-se as questões abertas, desse último.

$\mathrm{O}$ instrumento de Pilati, Porto e Silvino, 2007 foi composto por duas subescalas. $\mathrm{Na}$ primeira, de transferência de aprendizagem, cada um dos 18 itens deveria ser avaliado duas vezes, por duas escalas de resposta do tipo Likert, de cinco pontos, uma para domínio ( $1=$ não domino nada, 2 = domino pouco, 3 = domino medianamente, $4=$ domino muito, 5 = domino totalmente) e outra para frequência de uso da competência no trabalho ( $1=$ nunca, $2=$ raramente, 3 = algumas vezes, $4=$ frequentemente, $5=$ sempre). Cabe ressaltar que a aferição de transferência de aprendizagem é dada pela resposta à escala de frequência de uso do aprendido, que, por definição teórica, é o indicador mais frequentemente utilizado para aferição da efetividade do treinamento no trabalho (PILATI; PORTO; SILVINO, 2007). A escala 
de domínio é um indicador de retenção do aprendido, um dos efeitos esperados provocados por uma ação educacional. Além disso, a escala de domínio serve como estratégia comparativa e de tomada de decisões sobre a transferência de aprendizagem, pois permite avaliar a discrepância entre uso e domínio.

A segunda subescala é de impacto, e os sete foram respondidos usando a mesma escala de cinco pontos de freqüência, já citada.

O instrumento de Brandão, Bahry e Freitas (2008) continha três aspectos: (i) um item sobre o grau de aplicação das competências no trabalho, medido por meio de uma escala tipo Likert de 10 pontos(1=nunca e 10=sempre); (ii) o suporte à aplicação da aprendizagem, composta por 10 itens foi avaliada por meio de uma escala tipo Likert de 10 pontos (1= discordo totalmente e $10=$ concordo totalmente); e (iii) características individuais dos participantes, composto de sete itens, foi destinado ao levantamento de dados pessoais dos respondentes (gênero, tempo de serviço no Banco, local de trabalho, tempo de conclusão do curso de mestrado ou doutorado, entre outros).

Os itens de suporte à aplicação da aprendizagem usados nesta pesquisa foram construídos com base em escala de suporte validada por Araújo e Freitas (ARAÚJO; FREITAS, 2000), a qual inclui variáveis do contexto organizacional, tidas como importantes para favorecer a aplicação, no trabalho, de competências desenvolvidas em ações de aprendizagem. Essa escala possui dez itens, agrupados em dois fatores (suporte psicossocial e material). Tais itens passaram por uma pequena adequação semântica: os termos curso ou treinamento foram substituídos pela expressão mestrado ou doutorado.

A aplicação do questionário foi precedida por uma validação semântica, teste para verificar se o enunciado, a escala e os itens do instrumento eram inteligíveis aos respondentes, (PASQUALI, 1997). A validação semântica do instrumento de pesquisa foi realizada por 4 mestres que trabalham no Banco do Brasil, sendo dois deles egressos do Programa UniBB de Mestrado e Doutorado (um da modalidade bolsista e outro da modalidade pesquisador), contribuindo assim para se equalizar a linguagem acadêmica do instrumento com a cultura organizacional do Banco. Em função dessa avaliação, o questionário foi adaptado de Pilati, Porto e Silvino (2007) e de Brandão, Bahry e Freitas (2008), gerando sua versão final, apresentado no Apêndice.

\subsection{Coleta e tratamento de dados}

O questionário foi aplicado on-line, em ambiente virtual, no período de 8 de junho de 2013 a 29 de julho de 2013. O convite para participar da pesquisa foi enviado para os e-mails corporativos dos respondentes e continha instruções gerais sobre a pesquisa e era acompanhada de um link que disponibilizava o acesso ao questionário. $O$ questionário, por sua vez, possuía as informações necessárias para que os participantes da pesquisa pudessem respondê-los. Lembretes acerca do convite para participar da pesquisa foram reenviados por e-mail. O prazo para responder foi prorrogado uma vez.

Foram remetidos 172 questionários, sendo respondidos 121 e considerados com respostas válidas 107 questionários, sendo que 2 não responderam aos dados demográficos (questões 6 a 12), porém foram considerados na análise. Esse número corresponde a $62 \%$ dos egressos que foram convidados a participar da pesquisa. Essa alta taxa de resposta, se comparada à média geral de $30 \%$ nas pesquisas de avaliação de treinamento, foi possível em função do apoio da organização e da divulgação da ferramenta de pesquisa que permite emitir lembretes aos pesquisados.

A partir das respostas ao questionário, foi elaborado banco de dados para análise quantitativa e estatística. Para a análise dos dados foi usado o SPSS - Statistical Package for the Social Sciences. Foram executados os seguintes procedimentos: (i) análise exploratória e 
descritiva dos dados; (ii) análise fatorial exploratória dos itens referentes a cada constructo, análise dos fatores extraídos e de consistência interna $(\alpha)$ desses fatores; (iii) análise de correlação entre os fatores; e (iv) análise de regressão múltipla. Primeiramente, foi realizada análise preliminar exploratória dos dados obtidos com a finalidade de possibilitar a verificação da exatidão da entrada de dados, identificação de casos omissos por questão e por respondente, outliers univariados e multivariados. Em seguida foi realizada análise descritiva dos dados a fim de se obter medidas de tendência central, dispersão (desvio-padrão) e distribuição de frequências de respostas válidas coletadas junto aos participantes.

Posteriormente foi realizada análise fatorial exploratória dos itens dos constructos Domínio ou aprendizagem (bloco 1 do instrumento de pesquisa), Transferência (blocos 2 e 3), Efeito (bloco 4) e Suporte (bloco 5), com a finalidade de explorar a relação entre o conjunto de itens e identificar a existência de padrão de correlações entre eles, visando agrupá-los em fatores (variáveis não-observadas), para posteriormente analisar as relações e influências entre eles. Nesta etapa, utilizou-se o método de análise dos componentes principais (PC) para verificar a fatorabilidade da matriz de dados, por meio da análise das correlações entre os itens, medida de Kaiser-Meyer-Olkin (KMO) e teste de esfericidade de Bartlett, além de estimar preliminarmente o número de fatores. Em seguida, utilizou-se o método de fatoração dos eixos principais (PAF), com rotação oblíqua para obter as estruturas fatoriais. A análise de consistência interna (Alpha de Cronbach) dos itens foi aplicada aos fatores resultantes com a finalidade de validar estatisticamente os construtos e verificar o respectivo grau de confiabilidade. Na última etapa de análise dos dados, cuja finalidade era investigar a existência de preditores para a transferência da aprendizagem nas situações de trabalho (variável critério), foi realizada uma análise de correlações entre os construtos do modelo proposto e posteriormente em análise de Regressão Linear.

\section{RESULTADOS E DISCUSSÃO}

A caracterização demográfica dos sujeitos é apresentada na Tabela 1. Constatou-se que a maioria dos 107 respondentes é do sexo masculino $(73,8 \%)$, cursou mestrado pelo Programa UniBB de Mestrado e Doutorado (81,3\%), participou do Programa na condição de bolsista - sem afastamento do trabalho durante a realização dos créditos do curso $(55,1 \%)$. Quanto à área em que a maioria cursou o mestrado ou doutorado foi em Administração $(32,7 \%)$ e Economia (28,0\%), o que condiz com a atividade fim da empresa e concluíram o mestrado ou doutorado majoritariamente entre 2010 e 2011 anos (36,4\%). Atua em unidades estratégicas da empresa $(57,0 \%)$ e ocupa função de confiança do segmento gerencial $(47,7 \%)$.

\subsection{Análise exploratória dos dados}

$\mathrm{Na}$ análise exploratória dos dados, foram localizados 14 casos omissos por respondente, assim caracterizados os participantes que deixaram de responder mais de $30 \%$ do questionário, sendo excluídos da amostra. Com relação aos casos omissos por questão, não foram localizados itens com ausência de respostas superior a 5\%, motivo pelo qual não foi necessário efetuar a exclusão de itens. Não foram localizados casos de outliers invariados, pois nenhum respondente assinalou o mesmo grau de percepção e frequência em todos os itens do questionário, o que denotaria leniência ou desinteresse do respondente. Visando localizar a presença de casos extremos discordantes do restante da amostra, foi verificada a possível presença de outliers multivariados por meio da análise da distância de Mahalabonis $(p<0,001)$, não sendo identificados casos na amostra. 
Tabela 1 - Dados biográficos e funcionais dos sujeitos da pesquisa

\begin{tabular}{|c|c|c|c|}
\hline Variável & Descrição & $\begin{array}{l}\text { Frequência } \\
\text { Absoluta }\end{array}$ & $\begin{array}{l}\text { Frequência } \\
\text { Relativa (\%) }\end{array}$ \\
\hline \multirow{4}{*}{ Gênero } & Não Informado & 2 & 1,9 \\
\hline & Feminino & 26 & 24,3 \\
\hline & Masculino & 79 & 73,8 \\
\hline & Total & 107 & 100,0 \\
\hline \multirow{4}{*}{ Curso } & Não Informado & 2 & 1,9 \\
\hline & Doutorado & 18 & 16,8 \\
\hline & Mestrado & 87 & 81,3 \\
\hline & TOTAL & 107 & 100,0 \\
\hline \multirow{4}{*}{ Modalidade } & Não Informado & 2 & 1,9 \\
\hline & $\begin{array}{l}\text { Bolsista (não afastado do trabalho durante a realização } \\
\text { de créditos do curso) }\end{array}$ & 59 & 55,1 \\
\hline & $\begin{array}{l}\text { Pesquisador (afastamentoo parcial do trabalho durante } \\
\text { o curso) }\end{array}$ & 46 & 43,0 \\
\hline & Total & 107 & 100,0 \\
\hline \multirow{8}{*}{$\begin{array}{l}\text { Tempo de } \\
\text { formação }\end{array}$} & Não Informado & 2 & 1,9 \\
\hline & 1 a 2 anos & 39 & 36,4 \\
\hline & 3 a 4 anos & 24 & 22,4 \\
\hline & 5 a 6 anos & 16 & 15,0 \\
\hline & 7 a 8 anos & 4 & 3,7 \\
\hline & 9 a 10 anos & 7 & 6,5 \\
\hline & 11 anos ou mais & 15 & 14,0 \\
\hline & TOTAL & 107 & 100,0 \\
\hline \multirow{9}{*}{$\begin{array}{c}\text { Área de } \\
\text { conhecime } \\
\text { nto }\end{array}$} & Não Informado & 2 & 1,9 \\
\hline & Administração & 35 & 32,7 \\
\hline & Direito & 3 & 2,8 \\
\hline & Economia & 30 & 28,0 \\
\hline & Engenharia & 5 & 4,7 \\
\hline & Informática & 5 & 4,7 \\
\hline & Outros & 21 & 19,6 \\
\hline & Psicologia & 6 & 5,6 \\
\hline & TOTAL & 107 & 100,0 \\
\hline \multirow{7}{*}{$\begin{array}{l}\text { Local onde } \\
\text { atua }\end{array}$} & Não Informado & 2 & 1,9 \\
\hline & Outra & 2 & 1,9 \\
\hline & UA - Unidade de Apoio & 23 & 21,5 \\
\hline & UE - Unidade Estratégica & 61 & 57,0 \\
\hline & UN - Unidade de Negócios & 15 & 14,0 \\
\hline & UT - Unidade Tática & 4 & 3,7 \\
\hline & TOTAL & 107 & 100,0 \\
\hline \multirow{8}{*}{$\begin{array}{l}\text { Função que } \\
\text { exerce }\end{array}$} & Não Informado & 2 & 1,9 \\
\hline & De confiança do Segmento de Assessoramento & 43 & 40,2 \\
\hline & De confiança do Segmento Gerencial & 51 & 47,7 \\
\hline & Estatutário & 2 & 1,8 \\
\hline & $\begin{array}{l}\text { Gestão de Riscos e Integração Financeira na América } \\
\text { Latina }\end{array}$ & 1 & 0,9 \\
\hline & Gratificada do Segmento Operacional & 3 & 2,8 \\
\hline & Gratificada do Segmento Técnico & 5 & 4,7 \\
\hline & TOTAL & 107 & 100,0 \\
\hline
\end{tabular}

Perspectivas em Gestão \& Conhecimento, João Pessoa, v. 8, n. 1, p. 155-190, jan./abr. 2018. 


\subsection{Análise descritiva dos dados}

Foi realizada análise descritiva dos dados com a finalidade de se identificar as principais competências científicas desenvolvidas em curso de mestrado e/ou doutorado e aplicadas no Banco do Brasil, bem como os principais fatores de suporte à aplicação das competências científicas no Banco do Brasil.

Inicialmente, investigou-se junto aos egressos do Programa qual o nível de aprendizagem com relação às competências normalmente desenvolvidas ao longo do programa de pósgraduação. Para isso, os participantes manifestaram a sua percepção de domínio de 18 competências apresentadas e manifestaram-se por meio de escala de cinco pontos, onde um correspondia à "Não Domino Nada" e cinco correspondia à "Domino Totalmente". Na Tabela 2 são apresentadas as médias e desvios-padrão correspondentes à percepção do grau de domínio das competências apresentadas.

Tabela 2 - Nível de Aprendizagem - Domínio de Competências

\begin{tabular}{lccc}
\hline $\begin{array}{l}\text { Avalie o grau em que você desenvolveu essas competências no curso } \\
\text { de mestrado e/ou doutorado (domínio). }\end{array}$ & Média & $\begin{array}{c}\text { Desvio } \\
\text { Padrão }\end{array}$ & N \\
\hline Ler textos científicos na minha área de atuação. & 4,41 & 0,76 & 107 \\
\hline Analisar e sintetizar problemas na minha área de atuação. & 4,27 & 0,76 & 107 \\
\hline Coordenar equipes de trabalho. & 4,19 & 0,77 & 107 \\
\hline $\begin{array}{l}\text { Buscar conhecimentos científicos de vanguarda na minha área para } \\
\text { serem utilizados na organização }\end{array}$ & 4,10 & 0,80 & 107 \\
\hline Sistematizar informações para subsidiar decisões no trabalho. & 4,08 & 0,85 & 107 \\
\hline $\begin{array}{l}\text { Realizar trabalhos complexos que exigem análise crítica da situação e } \\
\text { proposições de soluções inovadoras. }\end{array}$ & 4,07 & 0,73 & 107 \\
\hline Transmitir o conhecimento por meio de palestras, aulas etc. & 4,00 & 0,88 & 107 \\
\hline $\begin{array}{l}\text { Relatar sistematicamente por escrito o conhecimento produzido (ex. } \\
\text { artigo científico). }\end{array}$ & 3,99 & 0,89 & 107 \\
\hline Participar na elaboração de projetos estratégicos. & 3,94 & 0,89 & 107 \\
\hline Sugerir novas metodologias de trabalho. & 3,93 & 0,84 & 107 \\
\hline $\begin{array}{l}\text { Analisar criticamente novas metodologias na minha área (modelos } \\
\text { econômicos, financeiros, administrativos etc.) }\end{array}$ & 3,91 & 0,89 & 107 \\
\hline $\begin{array}{l}\text { Desenvolver conhecimentos para dar suporte empírico às decisões da } \\
\text { chefia. }\end{array}$ & 3,91 & 0,81 & 107 \\
\hline Multiplicar o conhecimento apreendido na pós-graduação. & 3,91 & 0,87 \\
\hline Propor novos processos de trabalho. & 3,82 & 0,86 & 107 \\
\hline Realizar pesquisas aplicadas às necessidades da organização. & 3,77 & 0,88 & 107 \\
\hline $\begin{array}{l}\text { Desenvolver instrumentos para abordar problemas complexos da } \\
\text { realidade da organização. }\end{array}$ & 3,74 & 0,84 & 107 \\
\hline Proporcionar a interação entre a organização e a comunidade & 3,58 & 0,85 & 107 \\
\hline Proporcionar a interação entre a organização e o meio acadêmico. & 3,58 & 1,02 & 107 \\
\hline Resultado Geral & $\mathbf{3 , 9 6}$ & $\mathbf{0 , 8 4}$ & $\mathbf{1 0 7}$ \\
\hline Fonte: Dados da pesquisa, & & \\
\hline
\end{tabular}

Fonte: Dados da pesquisa, 2014

Nota-se o elevado nível de aprendizagem de competências, todas as variáveis pertencentes ao construto foram avaliadas com médias superiores à 3,5 e desvios-padrão máximos próximos de 1,0, o que demonstra que o Programa apresenta um elevado nível de aprendizagem e uma percepção pouco variada entre os respondentes. Os itens com maiores níveis de aprendizagem, segundo a percepção dos respondentes foram "Ler textos científicos na minha área de atuação" (média 4,41 e desvio-padrão 0,76), "Analisar e sintetizar problemas na minha área de atuação" (média 4,27 e desvio-padrão 0,76) e "Coordenar equipes de

Perspectivas em Gestão \& Conhecimento, João Pessoa, v. 8, n. 1, p. 155-190, jan./abr. 2018. 
trabalho" (média 4,19 e desvio-padrão 0,77), denotando que os egressos obtiveram aprendizagem referente a problematização e método científico.

Os itens com menores médias de percepção de aprendizagem foram "Desenvolver instrumentos para abordar problemas complexos da realidade da organização" (média 3,74 e desvio-padrão 0,84), "Proporcionar a interação entre a organização e a comunidade" (média 3,58 e desvio-padrão 0,85 ) e "Proporcionar a interação entre a organização e o meio acadêmico" (média 3,58 e desvio-padrão 1,02). Ressalte-se que mesmo os itens com piores avaliações obtiveram médias satisfatórias de aprendizagem.

Assim, se entende que as 15 horas semanais de trabalho que os pesquisadores realizam na empresa e a permanência das atividades laborais dos bolsistas enquanto realizam o mestrado ou doutorado, contribuem para a interação entre a organização e o meio acadêmico, embora apresentem potencial de melhoria.

Também, fica evidenciado que a participação em cursos stricto sensu desenvolvem competências específicas, de natureza científica, na percepção dos mestres e doutores. Constatada a percepção de aprendizagem, o foco é verificar em que grau as competências são utilizadas no trabalho.

Uma questão abrangente denominada Frequência de Aplicação das Competências Desenvolvidas, foi usada para avaliar a percepção dos egressos quanto à aplicação das competências científicas no trabalho. Esse único item foi mensurado por meio de uma escala Likert de frequência de dez pontos (variando de $1=$ nunca a $10=$ sempre). Constatou-se que os respondentes aplicam no trabalho, com razoável frequência (média 6,73 e desvio-padrão 2,45), as competências que desenvolveram em seus cursos de mestrado e doutorado. No entanto, o desvio-padrão indica que a percepção não é homogênea, alguns aplicam muito e outros não, resultado semelhante ao encontrado por Brandão, Bahry e Freitas, 2008.

A Tabela 3 identifica o grau de aplicação no trabalho das competências científicas desenvolvidas por mestres e doutores participantes do Programa UniBB de Mestrado e Doutorado. Os 18 itens foram avaliados por meio de escala Likert de frequência de cinco pontos, onde um correspondia à "Nunca" e cinco correspondia à "Sempre".

Tabela 3 - Frequência de uso do aprendido

\begin{tabular}{lccc}
\hline Avalie a frequência que você aplica essas competências no trabalho. & Média & $\begin{array}{c}\text { Desvio } \\
\text { Padrão }\end{array}$ & N \\
\hline Realizar trabalho em equipe & 3,86 & 0,98 & 107 \\
\hline Ler textos científicos relacionados à minha área de atuação & 3,65 & 1,13 & 107 \\
\hline Analisar e sintetizar problemas na minha área de atuação & 3,64 & 1,06 & 107 \\
\hline $\begin{array}{l}\text { Realizar trabalhos complexos que exigem análise crítica da situação e } \\
\text { proposições de soluções inovadoras }\end{array}$ & 3,43 & 0,99 & 107 \\
\hline Sistematizar informações para subsidiar decisões no BB & 3,41 & 1,17 & 107 \\
\hline $\begin{array}{l}\text { Desenvolver conhecimentos para dar suporte empírico às decisões da } \\
\text { chefia. }\end{array}$ & 3,26 & 1,20 & 107 \\
\hline $\begin{array}{l}\text { Buscar conhecimentos científicos de vanguarda na minha área para } \\
\text { serem utilizados no BB }\end{array}$ & 3,26 & 1,10 & 107 \\
\hline Sugerir novos métodos de trabalho. & 3,17 & 1,17 & 107 \\
\hline Multiplicar o conhecimento apreendido no mestrado e/ou doutorado & 3,15 & 1,25 & 107 \\
\hline $\begin{array}{l}\text { Analisar criticamente novas metodologias na minha área (modelos } \\
\text { econômicos, financeiros, administrativos etc.) }\end{array}$ & 3,13 & 1,12 & 107 \\
\hline Propor novos processos de trabalho. & & & 107 \\
\hline Contribuir na elaboração de projetos estratégicos. & 3,08 & 1,20 \\
\hline $\begin{array}{l}\text { Desenvolver instrumentos para abordar problemas } \\
\text { complexos da realidade. (ex. instrumentos de pesquisa, modelos) }\end{array}$ & 3,06 & 1,32 & 107 \\
\hline Transmitir o conhecimento por meio de palestras, aulas etc. & 3,05 & 1,17 & 107 \\
\hline Realizar pesquisas aplicadas às necessidades do BB. & 2,93 & 1,27 \\
\hline Relatar sistematicamente (de forma organizada) por escrito o & 2,93 & 1,27 & 107 \\
\hline
\end{tabular}

Perspectivas em Gestão \& Conhecimento, João Pessoa, v. 8, n. 1, p. 155-190, jan./abr. 2018. 


\begin{tabular}{llrr}
\hline conhecimento produzido (ex. artigo científico). & & \\
\hline Proporcionar a interação entre a organização e a sociedade & 2,89 & 1,22 & 107 \\
\hline Proporcionar a interação entre a organização e o meio acadêmico. & $\mathbf{2 , 7 5}$ & 1,16 & 107 \\
\hline Resultado Geral & $\mathbf{3 , 2 2}$ & $\mathbf{1 , 1 7}$ & $\mathbf{1 0 7}$ \\
\hline
\end{tabular}

Fonte: Dados da pesquisa, 2014

Nota-se, primeiramente, que apenas 3 variáveis apresentaram médias superiores à 3,5 e desvios-padrão inferiores à 1,2; demonstrando que os egressos aplicam moderadamente o aprendido no trabalho e que não há grandes discordâncias entre eles. Dentre os itens pesquisados, os que apresentaram maior frequência de utilização foram as competências: "Realizar trabalho em Equipe" (média 3,86 e desvio-padrão 0,98); "Ler textos científicos relacionados à minha área de atuação" (média 3,65 e desvio-padrão 1,13); e "Analisar e sintetizar problemas na minha área de atuação" (média 3,64 e desvio-padrão 1,06) o que indica que o Programa proporcionou aos egressos a possibilidade de utilização de competências não apenas vinculadas especificamente aos conteúdos abordados. Os itens com as menores frequências médias de utilização foram: "Realizar pesquisas aplicadas às necessidades do BB" e "Relatar sistematicamente (de forma organizada) por escrito o conhecimento produzido (ex. artigo científico)" (ambas com média 2,93 e desvio-padrão 1,27); "Proporcionar a interação entre a organização e a sociedade" (média 2,89 e desvio-padrão 1,22); "Proporcionar a interação entre a organização e o meio acadêmico" (média 2,75 e desvio-padrão 1,16).

Não se identifica na empresa estudada unidades de trabalho que tenham natureza exclusiva de pesquisa para que a frequência do uso das competências científicas seja intensa. Quando o egresso retorna às suas atividades laborais, ele se insere na rotina da empresa e suas competências científicas são acionadas sempre que surge uma necessidade ou oportunidade de aplicação. Assim, se entende como sendo este o motivo pelo qual a frequência de uso dessas competências está em sua maioria abaixo da média 3,5.

Nota-se também que a pior média (média 2,75 e desvio-padrão 1,16) diz respeito a "Proporcionar a interação entre a organização e o meio acadêmico", uma vez que ao entrar na rotina de trabalho, o egresso perde o vínculo assíduo de interação entre a empresa e o meio acadêmico. Por outro lado, essa competência foi a que teve uma das menores médias na escala de domínio, ou seja, foi pouco desenvolvida. Esse resultado sugere que ainda é necessária ações de aproximação entre academia e empresa.

Os participantes também foram convidados a expressar sua percepção acerca dos efeitos (contribuições) do Programa de Pós-Graduação sobre o próprio desempenho no trabalho desde a conclusão do curso até o fornecimento de respostas à pesquisa, por meio de 7 (sete) itens. Para responder aos itens os convidados utilizaram-se de escala Likert de frequência de 5 (cinco) pontos, onde 1 (um) correspondia à "Nunca" e 5 (cinco) correspondia à "Sempre". Na Tabela 4 são apresentadas as médias e desvios-padrão das respostas fornecidas pelos respondentes.

Tabela 4 - Efeito do Aprendido

\begin{tabular}{|c|c|c|c|}
\hline $\begin{array}{l}\text { Pense no efeito (contribuições) do mestrado e/ou doutorado para o } \\
\text { seu desempenho, desde a conclusão até o momento atual. }\end{array}$ & Média & $\begin{array}{l}\text { Desvio } \\
\text { Padrão }\end{array}$ & $\mathbf{N}$ \\
\hline $\begin{array}{l}\text { Após meu mestrado e/ou doutorado, tenho mantido bom } \\
\text { relacionamento interpessoal com colegas de trabalho. }\end{array}$ & 4,22 & 0,76 & 107 \\
\hline $\begin{array}{l}\text { A qualidade do meu trabalho tem melhorado mesmo naquelas } \\
\text { atividades que pareciam não estar relacionadas ao meu mestrado e/ou } \\
\text { doutorado. }\end{array}$ & 4,10 & 0,85 & 107 \\
\hline Após o meu mestrado e/ou doutorado, tenho cooperado com colegas & 3,88 & 0,79 & 107 \\
\hline
\end{tabular}




\begin{tabular}{|c|c|c|c|}
\hline $\begin{array}{l}\text { O mestrado e/ou doutorado que fiz tem me tornado mais receptivo a } \\
\text { mudanças no trabalho. }\end{array}$ & 3,80 & 1,03 & 107 \\
\hline $\begin{array}{l}\text { Minha participação no mestrado e/ou doutorado tem aumentado } \\
\text { minha motivação para trabalhar. }\end{array}$ & 3,79 & 1,05 & 107 \\
\hline $\begin{array}{l}\text { O mestrado e/ou doutorado que fiz tem beneficiado meus colegas de } \\
\text { trabalho, que tem aprendido comigo algumas novas habilidades. }\end{array}$ & 3,47 & 1,03 & 107 \\
\hline $\begin{array}{l}\text { Após minha participação no mestrado e/ou doutorado, tenho sugerido } \\
\text { mudanças nas rotinas de trabalho. }\end{array}$ & 3,40 & 1,08 & 107 \\
\hline Resultado Geral & 3,81 & 0,94 & 107 \\
\hline
\end{tabular}

Fonte: Dados da pesquisa, 2014

Verifica-se que os respondentes percebem o impacto positivo do curso de mestrado ou doutorado sobre o desempenho no trabalho (amplitude). A maioria dos itens respondidos foram avaliados com média acima de 3,5 e desvios-padrão menores que 1,2; demonstrando que, além de possuir efeitos positivos sobre o desempenho dos egressos do Programa, há pouca variabilidade de resposta aos itens. Os itens percebidos com maiores frequências médias foram "Após meu mestrado e/ou doutorado, tenho mantido bom relacionamento interpessoal com colegas de trabalho" (média 4,22 e desvio-padrão 0,76), "A qualidade do meu trabalho tem melhorado mesmo naquelas atividades que pareciam não estar relacionadas ao meu mestrado e/ou doutorado" (média 4,10 e desvio-padrão 0,85), indicando que a realização do curso contribuiu para o desempenho no trabalho. Já os itens com menores avaliações de frequência média foram "O mestrado e/ou doutorado que fiz tem beneficiado meus colegas de trabalho, que tem aprendido comigo algumas novas habilidades" (média 3,47 e desvio-padrão 1,03) e "Após minha participação no mestrado e/ou doutorado tenho sugerido mudanças nas rotinas de trabalho" (média 3,40 e desvio-padrão 1,08).

Note-se que após a conclusão do mestrado ou doutorado, o egresso do Programa UniBB percebe o efeito do curso ao longo de sua carreira profissional, contribuindo em seu ambiente de trabalho. Isto corrobora com a premissa que a entrega da dissertação ou tese não encerra a aplicação das competências científicas no trabalho, porém, uma vez estimulada a aplicação das competências científicas, o mestre ou doutor pode contribuir em diversas situações do trabalho. Contudo, poderiam ser também estimulados pelo BB a, formalmente e informalmente, compartilharem o "fazer científico" com seus colegas, uma das formas propostas por Davenport e Prussak (2003) para gerar e disseminar conhecimento dentro de uma organização.

Os egressos do programa, participantes da pesquisa, foram convidados a se manifestar a respeito do Suporte Material e Psicossocial prestado pelo Banco à aplicação do aprendido em situações de trabalho, ou seja, as condições físicas oferecidas e o quanto a empresa estimula e apoia o uso do aprendido e que consequências o egresso percebe ao utilizar as novas competências. Para responder aos 10 (dez) itens apresentados os respondentes utilizaram escala tipo Likert de concordância de 10 (dez) pontos, onde 1 (um) corresponde à "Discordo Totalmente" e 10 (dez) correspondia à "Concordo Totalmente". A Tabela 5 apresenta as médias e desvios-padrão das respostas coletadas.

Tabela 5 - Suporte à Aplicação das Competências

\begin{tabular}{lccc}
\hline Registre o grau de concordância que corresponde à sua percepção. & Média & $\begin{array}{c}\text { Desvio } \\
\text { Padrão }\end{array}$ & N \\
\hline $\begin{array}{l}\text { Sinto-me seguro em aplicar, no trabalho, o que aprendi no curso de } \\
\text { mestrado e/ou doutorado. }\end{array}$ & 7,94 & 2,53 & 106 \\
\hline $\begin{array}{l}\text { Considero-me motivado para utilizar, na situação de trabalho, as } \\
\text { competências que desenvolvi no curso de mestrado e/ou doutorado. }\end{array}$ & 7,16 & 2,99 & 106 \\
\hline
\end{tabular}

Perspectivas em Gestão \& Conhecimento, João Pessoa, v. 8, n. 1, p. 155-190, jan./abr. 2018. 


\begin{tabular}{lccc}
\hline $\begin{array}{l}\text { As condições físicas do meu ambiente de trabalho (espaço, iluminação, } \\
\text { mobiliário e outras) são adequadas à aplicação do que aprendi no meu }\end{array}$ & 6,86 & 2,95 & 106 \\
mestrado e/ou doutorado. & & \\
\hline $\begin{array}{l}\text { Após concluir o meu mestrado e/ou doutorado, trabalhei em área do } \\
\text { Banco que permitiu aplicar o que aprendi no curso. }\end{array}$ & 6,68 & 3,09 & 107 \\
\hline $\begin{array}{l}\text { Meus colegas apoiam as tentativas que faço de usar, no trabalho, o } \\
\text { que aprendi no curso de mestrado e/ou doutorado. }\end{array}$ & 6,11 & 2,65 & 107 \\
\hline $\begin{array}{l}\text { Tenho recebido elogios quando aplico corretamente, no trabalho, as } \\
\text { novas competências que desenvolvi no curso de mestrado e/ou } \\
\text { doutorado. }\end{array}$ & 5,92 & 2,94 & 106 \\
\hline $\begin{array}{l}\text { Tenho acesso às informações necessárias para a correta aplicação, no } \\
\text { trabalho, do que aprendi no curso de mestrado e/ou doutorado. }\end{array}$ & 5,58 & 2,98 & 107 \\
\hline $\begin{array}{l}\text { Meu gerente imediato tem me estimulado quanto à aplicação, no } \\
\text { trabalho, do que aprendi no curso de mestrado e/ou doutorado. }\end{array}$ & 5,29 & 3,12 & 107 \\
\hline $\begin{array}{l}\text { O Banco tem colocado à minha disposição os recursos materiais } \\
\text { necessários para que eu possa aplicar, no trabalho, o que aprendi no } \\
\text { curso de mestrado/doutorado. }\end{array}$ & 5,21 & 2,94 & 107 \\
\hline $\begin{array}{l}\text { Sou orientado quando cometo erros ao aplicar as competências que } \\
\text { desenvolvi no curso de mestrado e/ou doutorado. }\end{array}$ & 4,10 & 2,93 & 106 \\
\hline Resultado Geral & & $\mathbf{6 , 0 9}$ & $\mathbf{2 , 9 1}$ \\
\hline
\end{tabular}

Fonte: Dados da pesquisa, 2014

Os itens com maior percepção acerca do suporte à aplicação das competências desenvolvidas no curso de mestrado e/ou doutorado foram "Sinto-me seguro em aplicar, no trabalho, o que aprendi no curso de mestrado e/ou doutorado" (média 7,94 e desvio-padrão $2,53)$ e "Considero-me motivado para utilizar, na situação de trabalho, as competências que desenvolvi no curso de mestrado e/ou doutorado" (média 7,16 e desvio-padrão 2,99). A média acima de 6,50 nestas questões leva a inferir que, ao longo da vida profissional, o egresso do Programa mantém a disposição e o apoio da organização para a aplicação das competências profissionais desenvolvidas no mestrado e/ou doutorado. Já as questões com as menores médias foram "O Banco tem colocado à minha disposição os recursos materiais necessários para que eu possa aplicar, no trabalho, o que aprendi no curso de mestrado/doutorado" (média 5,21 e desvio-padrão 2,94) e "Sou orientado quando cometo erros ao aplicar as competências que desenvolvi no curso de mestrado e/ou doutorado" (média 4,10 e desviopadrão 2,93). Destaca-se também que em todos os itens avaliados o desvio-padrão é alto, o que indica heterogeneidade na percepção dos respondentes sobre o suporte oferecido pela empresa, ou seja, alguns percebem alto suporte e outros não. Não se observa concentração de respostas referente suporte psicossocial ou material. As respostas estão balanceadas entre essas perspectivas. No entanto, as maiores médias das respostas referem-se à atitude do egresso em relação ao trabalho. Já as menores médias em sua maioria, dizem respeito à percepção dos egressos quanto às atitudes de seus colegas e superior em relação a ele. Assim, poderia O BB além de orientar o egresso para seu retorno à equipe, também estimular a equipe de trabalho a acolher o egresso e apoiá-lo ainda mais na aplicação das competências científicas.

\subsection{Análises fatoriais - Qualidade das medidas}

Ainda na fase exploratória dos dados obtidos na pesquisa, com a finalidade de combinar os itens originais em um conjunto menor de variáveis com a perda mínima de informações a partir da identificação de padrões de correlação, foram realizadas análises fatoriais exploratórias com os itens sobre: Domínio de competências proporcionado pela

Perspectivas em Gestão \& Conhecimento, João Pessoa, v. 8, n. 1, p. 155-190, jan./abr. 2018. 
participação no Programa; Efeito da Participação no Programa sobre o desempenho no trabalho; Transferência do aprendido para situações de trabalho; e Suporte e Apoio organizacional à transferência do aprendido, resultando na criação de fatores para utilização na análise de regressão. Inicialmente foi verificada a existência de condições de fatorabilidade dos itens de cada constructo estudado com finalidade de verificar a adequação amostral para as análises, sendo utilizados os seguintes critérios: análise da matriz de correlações e medida de Kaiser-Meyer-Olkin (KMO). Para isso foram conduzidas análises dos componentes principais (PC) nos itens de cada um dos constructos pesquisados, foi escolhida rotação oblíqua devido à suposição da existência de correlação entre os itens, em amostra de 107 respondentes, conforme a Tabela 6.

Tabela 6 - Fatorabilidade dos itens dos constructos pesquisados

\begin{tabular}{lcc}
\hline \multicolumn{1}{c}{ Constructo } & Correlações entre os itens & KMO \\
\hline Transferência & $0,47-0,74$ & 0,94 \\
\hline Domínio & $0,42-0,67$ & 0,93 \\
\hline Efeito & $0,24-0,48$ & 0,85 \\
\hline Suporte & $0,34-0,66$ & 0,90 \\
\hline
\end{tabular}

Fonte: Dados da pesquisa, 2014

A análise de fatorabilidade dos itens demonstrou: valores positivos de correlação entre os itens de todos os constructos; valores de KMO no mínimo bom, assim considerados aqueles entre 0,85 e 0,94 .

Os dados apresentados indicam a adequação suficiente das correlações entre os itens para a realização de Análises Fatoriais Exploratória, assim foram realizadas as análises, utilizando-se o método Fatoração de Eixo Principal (PAF), com rotação oblíqua.

Análise Fatorial - Transferência do Aprendido para Situações de Trabalho. A Fatoração de Eixo Principal demonstrou que um componente obedeceu ao critério de Kaiser do autovalor (eingenvalue) maior que 1 e explicou 66,52\% da variância. O scree plot mostrou que o componente está posicionado antes da inflexão. Considerando o tamanho da amostra (n: 107) e a convergência entre o scree plot e o critério de Kaiser, foi mantido um componente para o constructo "Transferência", extraído na análise final, com cargas fatoriais entre 0,54 e 0,86. Para avaliar a confiabilidade do fator, foi avaliado o coeficiente alfa de Cronbach, resultando em $\alpha=0,96$, indicando alta consistência interna entre os itens estudados.

Análise Fatorial - Domínio de competências. A Fatoração de Eixo Principal demonstrou que dois componentes obedeceram ao critério de Kaiser do autovalor (eingenvalue) maior que $1 \mathrm{e}$ explicaram, respectivamente, $53,6 \%$ e $7,09 \%$ da variância. 0 scree plot mostrou que ambos componentes estão posicionados antes da inflexão. Devido a pequena explicação da variância do componente 2, foi mantido o componente 1para o constructo "Domínio", extraído na análise final, com cargas fatoriais entre 0,64 e 0,80. Para avaliar a confiabilidade do fator Domínio, foi avaliado o coeficiente alfa de Cronbach do componente, resultando em $\alpha=0,92$, indicando alta consistência interna entre os itens estudados.

Análise Fatorial - Efeito da Participação no Programa. A Fatoração de Eixo Principal demonstrou que apenas um componente obedeceu ao critério de Kaiser do autovalor (eingenvalue) maior que 1 e explicou $52,75 \%$ da variância. O scree plot mostrou que o componente está posicionado antes da inflexão. Considerando o tamanho da amostra (n: 107) e a convergência entre o scree plot, o critério de Kaiser e o eingenvalue, foi mantido um componente para o constructo "Efeito", extraído na análise final, com cargas fatoriais entre

Perspectivas em Gestão \& Conhecimento, João Pessoa, v. 8, n. 1, p. 155-190, jan./abr. 2018. 
0,48 e 0,79 . Para avaliar a confiabilidade do fator Efeito, foi avaliado o coeficiente alfa de Cronbach do componente, resultando em $\alpha=0,96$, indicando a alta consistência interna entre os itens estudados.

Análise Fatorial - Suporte à aplicação do aprendido. A Fatoração de Eixo Principal demonstrou que apenas um componente obedeceu ao critério de Kaiser do autovalor (eingenvalue) maior que 1 e explicou $61,90 \%$ da variância. O scree plot mostrou que o componente está posicionado antes da inflexão. Considerando o tamanho da amostra ( $n=$ 107) e a convergência entre o scree plot e o critério de Kaiser, foi mantido um componente para o constructo "Suporte", extraído na análise final, com cargas fatoriais entre 0,59 e 0,89. Para avaliar a confiabilidade do fator Suporte, foi avaliado o coeficiente alfa de Cronbach do componente, resultando em $\alpha=0,93$, indicando a alta consistência interna entre os itens estudados.

Análise de Correlação entre as variáveis. Para se verificar a existência de associação entre as variáveis, foi realizada análise de correlações. Foram verificadas relações positivas e significativas entre as variáveis estudadas, conforme mostrado na Tabela 7.

Tabela 7 - Fatorabilidade dos itens dos constructos pesquisados (Correlação de Pearson)

\begin{tabular}{r|cccc}
\cline { 2 - 4 } & Domínio & Transferência & Efeito & Suporte \\
\hline Domínio & 1,0 & & & \\
\hline Transferência &, $42^{*}$ & 1,0 & & \\
\hline Efeito &, $42^{*}$ &, $67^{*}$ & 1,0 & 1,0 \\
\hline Suporte &, $41^{*}$ &, $66^{*}$ &, $66^{*}$ &
\end{tabular}

Fonte: Dados da pesquisa, 2014

Os resultados indicam que há correlação significativa entre todos os constructo pesquisados. A maior correlação é entre transferência (grau em que o egresso aplica a aprendizagem adquirida) e o efeito sobre o seu desempenho. Outra correlação muito importante é entre transferência e percepção de suporte à aplicação.

\subsection{Regressão linear}

Para investigar as características da amostra que pudessem influenciar as relações entre as variáveis estudas (em razão de seu gênero, tipo de curso realizado, a modalidade de participação no Programa UniBB de Mestrado e Doutorado, há quanto tempo que se deu a conclusão do curso, área de conhecimento, local de trabalho e função exercida) realizou-se a análise de variância (ANOVA One-Way). Cada uma dessas variáveis (dados pessoais dos respondentes) foi introduzida separadamente, como variável de controle, para verificar possíveis influências sobre a percepção acerca do suporte à transferência da aprendizagem e, depois, sobre a expressão de competências científicas no trabalho.

A normalidade das distribuições foi verificada examinando-se os índices de skewness e kurtosis das variáveis, os quais indicaram a ausência de distribuição normal em algumas delas (leve assimetria negativa). Embora a normalidade constitua um pressuposto, segundo Miles e Shevlin (2001), curtoses e assimetrias leves ou moderadas (inferiores a $\pm 1,0$ ) geralmente causam pouco problema em análises de regressão, gerando pouco ou nenhum efeito sobre os parâmetros estimados, em especial em grandes amostras. Transformações nas variáveis, por outro lado, poderiam normalizar as distribuições, mas gerariam outro problema: a dificuldade de interpretação dos resultados. 
Sobre o exame desses pressupostos, vale ressaltar que a linearidade das relações foi verificada por meio de gráficos de dispersão e do índice $R$ Square Linear $\left(R^{2}\right)$. Pode-se constar que as observações tendiam acompanhar as linhas de ajuste. $O$ índice $R^{2}$ revelou-se superior a 0,44 em alguns casos, indicando a presença de relação linear moderada ou forte na maioria das relações examinadas.

Utilizou-se análise de regressão múltipla sequencial, com nível de significância $\rho \leq 0,05$, para identificar variáveis antecedentes (fatores de suporte à transferência e características individuais) que explicavam a variância do grau de aplicação das competências científicas no trabalho (variável critério). Inicialmente, para verificar a adequação dos dados a análise de regressão, foram verificados os pressupostos: coeficientes de variação, tamanho da amostra, normalidade das distribuições, correlações entre variáveis, homoscedasticidade, multicolinearidade e linearidade das relações entre as variáveis antecedentes e critério, conforme sugere Pasquali (2006).

Além disso, depois de realizadas as análises, se verificou que a distribuição dos resíduos padronizados era aproximadamente normal e que o gráfico de dispersão dos resíduos não apresentou formato em $U$, reta ou espaçamento ascendente. Essa ausência de padrão na plotagem dos resíduos, segundo Hair Jr. et al. (2005), sugere a inexistência de correlação entre eles e a presença de linearidade e de homogeneidade. Pôde-se confirmar, também, a ausência de pressuposto, uma vez que os parâmetros estimados revelaram tolerâncias superiores a 0,1 e estatísticas VIF inferiores a 3. Tais aspectos indicaram a adequação dos dados à regressão, sugerindo a possibilidade de inclusão de uma variável antecedente no modelo: fator Suporte. Essa análise revelou que o melhor modelo era composto por apenas uma variável preditora: o Suporte foi responsável por $44 \%$ da variância. Esse fator explicou $44 \%$ da aplicação, no trabalho, das competências científicas desenvolvidas em cursos de mestrado e/ou doutorado (variável critério). As demais variáveis não atuaram como preditoras significativas.

$O$ coeficiente $\beta$ de 0,66 positivo indica que, quanto melhor a percepção acerca do suporte oferecido pela empresa, maior o grau de aplicação das competências desenvolvidas pelos funcionários. O Suporte revelou-se como o único preditor da expressão de competências no trabalho. As variáveis individuais não foram preditoras. Esse resultado corrobora os achados de Brandão, Bahry e Freitas (2008) e os principais resultados de pesquisa na área que indica o suporte à transferência como principal preditor de impacto de treinamento (aplicação da aprendizagem).

Os resultados da pesquisa indicam que as competências científicas desenvolvidas pelos mestres e doutores são aplicadas no trabalho, tendo o Suporte como fator preditivo para essa aplicação. Isto demonstra que a Empresa estudada deve estimular o trabalho dos mestres e doutores, proporcionando condições materiais e psicossociais adequadas para o desenvolvimento de suas atividades a fim de obter o melhor aproveitamento de sua capacidade produtiva, por meio da aplicação das competências científicas desenvolvidas.

\section{CONCLUSÃO}

Para atingir o objetivo geral desta pesquisa, realizada no âmbito de uma dissertação de mestrado (ALMEIDA, 2014), de verificar a aplicação de competências científicas no Banco do Brasil adquiridas por meio do seu programa de capacitação em nível stricto sensu, utilizaramse instrumentos construídos em outros estudos (PILATI, PORTO e SILVINO, 2007; BRANDÃO, BAHRY e FREITAS, 2008) e que passaram por um processo de adaptação e validação. O estudo demonstrou que ocorre, no Banco do Brasil, a aplicação das competências científicas desenvolvidas nos cursos de mestrado e doutorado. Nesse sentido, sugere-se para estudos futuros que o instrumento validado seja aplicado em diferentes contextos e amostras, a fim de aumentar a generalidade dos resultados da pesquisa.

Perspectivas em Gestão \& Conhecimento, João Pessoa, v. 8, n. 1, p. 155-190, jan./abr. 2018. 
O fator Suporte apresenta-se como preditor da aplicação das competências, reforçando a necessidade da organização oferecer condições para a transferência da aprendizagem ocorrida em cursos de mestrado e doutorado.

A estratégia das Universidades Corporativas de incentivar o desenvolvimento de novas competências, inclusive, competências científicas, demonstra que ocorre o retorno sob o ponto de vista da aplicação das competências científicas aprendidas. No caso específico do Banco do Brasil, percebe-se, então, que a aprendizagem ocorrida no meio acadêmico não se restringe ao desenvolvimento de dissertação ou tese, porém, as competências científicas desenvolvidas permanecem sendo aplicadas pelos egressos ao longo de sua vida profissional. Todavia, tão importante quanto conceder bolsas de estudo para cursos stricto sensu é oferecer o apoio necessário aos egressos desses cursos para que façam uso das novas competências no trabalho. Sobre esse aspecto, sugere-se, em estudos posteriores, investigar o papel dos gestores no suporte à aplicação das competências científicas no trabalho.

Os objetivos específicos deste estudo também foram alcançados, uma vez que foram identificadas as principais competências científicas desenvolvidas por mestres e doutores participantes do Programa UniBB de Mestrado e Doutorado, as principais competências científicas usadas no trabalho e os principais fatores de suporte à aplicação dessas competências no Banco do Brasil.

O conhecimento científico, devido ao seu contexto metodológico, uma vez aplicado no trabalho, pode gerar um diferencial competitivo para a empresa. Assim, quanto à gestão do conhecimento científico, sugere-se para estudos futuros a investigação da possibilidade da criação de conhecimento científico no ambiente empresarial a partir da atuação conjunta de mestre e doutores de uma mesma organização.

Contribuições importantes desta pesquisa referem-se ao tema competências científicas, ampliando, assim, a discussão sobre o assunto. Outra contribuição refere-se à junção de dois instrumentos de pesquisa que possibilitaram investigar conjuntamente os aspectos de domínio, transferência, efeito e suporte à aplicação das competências científicas no trabalho. No que diz respeito à escala desenvolvida por Pilati, Porto e Silvino (2007), foi aplicada em uma instituição diferente daquela por eles pesquisados, visando à aferição de transferência de aprendizagem e impacto no trabalho de programas de mestrado e doutores de outras organizações, conforme sugerido pelos autores. Quanto ao instrumento desenvolvido por Brandão, Bahry e Freitas (2008), a contribuição foi a aplicação da pesquisa, oito anos após o estudo realizado pelos autores, na mesma instituição, proporcionando assim a continuidade na obtenção de dados referente à importância da percepção do suporte à transferência no programa de mestrado e doutorado. Outro aspecto relevante é que, pela primeira vez, os mestres e doutores que participaram do Programa na modalidade bolsista foram pesquisados e os resultados demonstraram não haver diferenciação entre a percepção desses participantes e os da modalidade pesquisador.

Quanto às limitações da pesquisa, pode-se destacar o universo de mestres e doutores pesquisados. Considerando que são participantes de programa institucional de mestrado e doutorado, podem trazer consigo, como forma de retribuição, além da dissertação ou tese, o compromisso de aplicarem no trabalho os conhecimentos desenvolvidos no trabalho. Embora o presente estudo amplie o enfoque da aprendizagem do conhecimento, incluindo a aprendizagem de habilidades e atitudes - competências científicas - desenvolvidas nos cursos de mestrado e doutorado, sugere-se aplicar o presente estudo no universo total de mestres e doutores do Banco do Brasil, comparando os resultados dos participantes do programa institucional e os mestres e doutores que realizaram o curso por inciativa própria.

Finalmente, os resultados alcançados, a nosso ver, evidenciam os benefícios da sinergia entre educação corporativa e a academia.

Perspectivas em Gestão \& Conhecimento, João Pessoa, v. 8, n. 1, p. 155-190, jan./abr. 2018. 


\section{REFERÊNCIAS}

ALMEIDA, G. P. A aplicação de competências científicas no trabalho: um estudo no Banco do Brasil. 2014. Dissertação (Mestrado) - Curso de Gestão do Conhecimento e Tecnologia da Informação, Universidade Católica de Brasília, Brasília, 2014.

BAHRY, C. P.; TOLFO, S. R. Mobilização de competências nas atividades profissionais dos egressos de um programa de formação e aperfeiçoamento. Revista de Administração Pública, v. 41, n. 1, p. 125-44, 2007.

BRANDÃO, H. P. Competências no trabalho: uma análise da produção científica brasileira. Estudos de Psicologia, v. 12, n. 2, p. 149-158, 2007.

BRANDÃO, H. P.; BAHRY, C. P. Gestão por competências: métodos e técnicas para mapeamento de competências. Revista do Serviço Público, v. 56, n. 2, p. 179-194, 2005.

BRANDÃO, H. P.; MOREIRA, I.; LEITE, J. B. D.; CARBONE, P. P.; VILHENA, R. M. Gestão por Competências e Gestão do Conhecimento. Rio de Janeiro: Editora FGV, 2005.

BRANDÃO, H. P.; BAHRY, C. P.; FREITAS, I. A. Os impactos do suporte à transferência sobre a aplicação de competências no trabalho: a percepção dos mestres e doutores do Banco do Brasil. Revista de Administração, v. 43, n. 3, p. 224-237, 2008.

BRANDÃO, H. P.; GUIMARAES, T. A. Gestão de competências e gestão de desempenho: tecnologias distintas ou instrumentos de um mesmo construto? Revista de Administração de Empresas, v. 41, n. 1, p. 8-15, 2001.

COSTA, H. V.; LEITE, J. B. D.; CARBONE, P. P. Experiências de Gestão do Conhecimento no Banco do Brasil. In: TERRA, José Cláudio Cyrineu. Gestão do Conhecimento e E-learning na Prática. Rio de Janeiro: Elsevier, 2003. Cap. 2, p. 13-18.

DAVENPORT, T. H.; PRUSAK, L. Conhecimento Empresarial: como as organizações gerenciam o seu capital intelectual. 15. ed. Rio de Janeiro: Elsevier, 2003.

DUARTE, E. N.; PAIVA, S. B.; SILVA, A. K. A. Gestão do conhecimento científico no contexto das bibliotecas universitárias. Cadernos de Biblioteconomia Arquivística e Documentação Cadernos BAD, n. 2, p. 69-81, 2007.

EBOLI, M. O desenvolvimento das pessoas e a educação corporativa. In: FLEURY, Maria Tereza Leme (Org.). As Pessoas na Organização. São Paulo: Gente, 2002. p. 185-216.

EBOLI, M.; HOURNEAUX Jr, F.; MANCINI, S. Breve panorama da educação corporativa no Brasil: apresentação de resultados de pesquisa. In: ANAIS DO XXIX ENANPAD - ENCONTRO DA ASSOCIAÇÃO NACIONAL DOS PROGRAMAS DE PÓS-GRADUAÇÃO EM ADMINISTRAÇÃO, Brasília, 2005.

FERREIRA, M. A. Estudo sobre a utilização de ferramentas de colaboração em redes de pesquisa científica. 2010. Dissertação (Mestrado) - Curso de Gestão do Conhecimento e Tecnologia da Informação, Universidade Católica de Brasília, Brasília, 2010. 
FREITAS, I. A.; BRANDÃO, H. P. Trilhas de aprendizagem como estratégia para desenvolvimento de competências. In: Anais do $29^{\circ}$ Encontro da Associação Nacional de Pós-Graduação e Pesquisa em Administração - EnANPAD. Brasília: ANPAD, 2005. Disponível em: $<$ http://www.anpad.org.br/diversos/trabalhos/EnANPAD/enanpad 2005/GPR/2005 GPRA316 .pdf>.

KROGH, G. von; ICHIJO, K.; NONAKA, I. Facilitando a criação de conhecimento: reinventando a empresa com o poder da inovação contínua. Rio de Janeiro: Campus, 2001.

LEITE, F. C. L. Gestão do conhecimento científico no contexto acadêmico: proposta de um modelo conceitual. 2006. Dissertação (Mestrado) - Curso de Ciência da Informação, Departamento de Ciência da Informação e Documentação, Universidade de Brasília, Brasília, 2006.

LEITE, F. C. L.; COSTA, S. Repositórios institucionais como ferramentas de gestão do conhecimento científico no ambiente acadêmico. Perspectivas em Ciência da Informação, v. 11, n. 2, p. 206-219, 2006.

MACIAS-CHAPULA, C. A. O papel da informetria e da cienciometria e sua perspectiva nacional e internacional. Ciência da Informação, v. 27, n. 2, p.134-140, 1998.

MARCONI, M. A.; LAKATOS, E. M. Fundamentos da Metodologia Científica. 5. ed. São Paulo: Atlas, 2003.

MARCONI, M. A.; LAKATOS, E. M. Metodologia Científica. 6. ed. São Paulo: Atlas, 2011.

MENINO, S. E. Formação Tecnológica para a Sociedade do Conhecimento. 2004. Dissertação (Mestrado) - Curso de Tecnologia, Centro Estadual de Educação Tecnológica Paula Souza, São Paulo, 2004.

MIRANDA, R. C. R. Gestão do conhecimento estratégico: uma proposta de modelo integrado. Tese (Doutorado em Ciência da Informação) - Universidade de Brasília: Brasília, 2004.

NONAKA, I.; TAKEUCHI, H. Criação de Conhecimento na Empresa: como as empresas japonesas geram a dinâmica da inovação. 19. ed. Rio de Janeiro: Elsevier, 1997.

PAIVA, S. B.; ARAGÃO, P. O. R.; PEREIRA, S. L. Gestão do Conhecimento em uma organização baseada em conhecimento: uma abordagem qualitativa. Produto \& Produção, v. 8, n. 2, p.3756, 2005.

PAIVA, S. B.; DUARTE, E. N. Da Gestão do Conhecimento Organizacional à Gestão do Conhecimento Científico: estratégias aplicáveis ao ambiente acadêmico. Conceitos, v. 6, n.14, p. 28-35. 2006.

PAIVA; S. B.; FERREIRA, H. M. C. Modelo de Gestão do Conhecimento aplicado ao contexto acadêmico: uma percepção de docentes universitários. In: XI Seminários em Administração FEA-USP (SEMEAD), 2008. Anais eletrônicos... São Paulo: FEA/USP, 2008. Disponível em: <http://sistema.semead.com.br/11semead/resultado/trabalhosPDF/518.pdf>.

PILATI, R.; PORTO, J. B.; SILVINO, A. M. D. Validação de medidas de efetividade de cursos de 
mestrado e doutorado no trabalho. Revista de Psicologia Organizacional e do Trabalho, v. 7, n. 2, 2007. Disponível em <http://pepsic.bvsalud.org/pdf/rpot/v7n2/v7n2a05.pdf>.

ROVER, A. (Org.). Metodologia científica: educação a distância. Joaçaba: Unoesc, 2006.

SIMIONI, M.; CAMPANHOLO, T. Universidades Corporativas: vantagem competitiva com a gestão do conhecimento. Revista da Católica, Uberlândia, v. 3, n. 5, 2011. Disponível em: $<$ http://catolicaonline.com.br/revistadacatolica2/artigosv3n5/artigo02.pdf>.

STRAUSS, A.; CORBIN, J. Introdução. In: STRAUSS, Anselm; CORBIN, Juliet. Pesquisa Qualitativa: técnicas e procedimentos para o desenvolvimento de teoria fundamentada. 2. ed. São Paulo: Artmed Editora S.A., 2008. Cap. 1, p. 17-27.

SVEIBY, K. E. A Nova Riqueza das Organizações: gerenciando e avaliando patrimônios de conhecimento. Rio de Janeiro: Campus, 1998.

TERRA, J. C. C. Gestão do Conhecimento: o grande desafio empresarial: uma abordagem baseada no aprendizado e na criatividade. 2. ed. São Paulo: Negócio Editora, 2001.

VELHO, L. O papel da formação de pesquisadores no sistema de inovação. Ciência e Cultura. v. 59, n. 4, p. 23-28, 2007.

Artigo recebido em 19/12/2016 e aceito para publicação em 08/11/2017 
APÊNDICE: QUESTIONÁRIO PARA COLETA DE DADOS [Adaptado de Pilati, Porto e Silvino (2007) e de Brandão, Bahry e Freitas (2008)]

1 - Nível De APRENDIZAGeM-DOMíNIo [1 = não domino nada, ..., 5 = domino totalmente]

- Realizar trabalhos complexos que exigem análise crítica da situação e proposições de soluções inovadoras.

- Buscar conhecimentos científicos de vanguarda na minha área para serem utilizados no BB.

- Analisar criticamente novas metodologias na minha área (modelos econômicos, financeiros, administrativos etc.)

- Desenvolver instrumentos para abordar problemas complexos da realidade. (ex. instrumentos de pesquisa, modelos)

- Ler textos científicos relacionados à minha área de atuação.

- Analisar e sintetizar problemas na minha área de atuação.

- Sistematizar informações para subsidiar decisões no BB.

- Proporcionar a interação entre a organização e o meio acadêmico.

- Realizar pesquisas aplicadas às necessidades do BB.

- Transmitir o conhecimento por meio de palestras, aulas etc.

- Desenvolver conhecimentos para dar suporte empírico às decisões da chefia.

- Sugerir novos métodos de trabalho.

- Multiplicar o conhecimento apreendido no mestrado e/ou doutorado.

- Contribuir na elaboração de projetos estratégicos.

- Relatar sistematicamente (de forma organizada) por escrito o conhecimento produzido (ex. artigo científico).

- Propor novos processos de trabalho.

- Realizar trabalho em equipe.

- Proporcionar a interação entre a organização e a sociedade

2 - Frequência de aplicação das competências desenvolvidas [1 = nunca, ..., 10 = sempre]

- Aplico, no meu trabalho, as competências desenvolvidas no curso de mestrado e/ou doutorado que realizei.

3 - Transferência de Aprendizagem - frequência de uso [1 = nunca, ..., 10 = sempre]

- Realizar trabalhos complexos que exigem análise crítica da situação e proposições de soluções inovadoras.

- Buscar conhecimentos científicos de vanguarda na minha área para serem utilizados no BB.

- Analisar criticamente novas metodologias na minha área (modelos econômicos, financeiros, administrativos etc.)

- Desenvolver instrumentos para abordar problemas complexos da realidade. (ex. instrumentos de pesquisa, modelos)

- Ler textos científicos relacionados à minha área de atuação.

- Analisar e sintetizar problemas na minha área de atuação.

- Sistematizar informações para subsidiar decisões no BB.

- Proporcionar a interação entre a organização e o meio acadêmico.

- Realizar pesquisas aplicadas às necessidades do BB.

- Transmitir o conhecimento por meio de palestras, aulas etc.

- Desenvolver conhecimentos para dar suporte empírico às decisões da chefia.

- Sugerir novos métodos de trabalho.

- Multiplicar o conhecimento apreendido no mestrado e/ou doutorado.

- Contribuir na elaboração de projetos estratégicos.

- Relatar sistematicamente (de forma organizada) por escrito o conhecimento produzido (ex. artigo 
científico).

- Propor novos processos de trabalho.

- Realizar trabalho em equipe.

- Proporcionar a interação entre a organização e a sociedade

4 - Efeito do Programa de Mestrado e/ou Doutorado sobre o desempenho [1 = nunca, ..., 10 = sempre]

- Minha participação no mestrado e/ou doutorado tem aumentado minha motivação para trabalhar.

- Após minha participação no mestrado e/ou doutorado tenho sugerido mudanças nas rotinas de trabalho.

- O mestrado e/ou doutorado que fiz tem me tornado mais receptivo a mudanças no trabalho.

- O mestrado e/ou doutorado que fiz tem beneficiado meus colegas de trabalho, que tem aprendido comigo algumas novas habilidades.

- Após o meu mestrado e/ou doutorado, tenho cooperado com colegas de trabalho na realização de suas atividades.

- A qualidade do meu trabalho tem melhorado mesmo naquelas atividades que pareciam não estar relacionadas ao meu mestrado e/ou doutorado.

- Após meu mestrado e/ou doutorado, tenho mantido bom relacionamento interpessoal com colegas de trabalho.

5 - Percepção de suporte À aplicaÇão das COMPetênCIAS [1 = discordo totalmente, ..., 10 = Concordo totalmente]

- Após concluir o meu mestrado e/ou doutorado, trabalhei em área do Banco que permitiu aplicar o que aprendi no curso.

- Meu gerente imediato tem me estimulado quanto à aplicação, no trabalho, do que aprendi no curso de mestrado e/ou doutorado.

- Meus colegas apoiam as tentativas que faço de usar, no trabalho, o que aprendi no curso de mestrado e/ou doutorado.

- O Banco tem colocado à minha disposição os recursos materiais necessários para que eu possa aplicar, no trabalho, o que aprendi no curso de mestrado/doutorado.

- Tenho acesso às informações necessárias para a correta aplicação, no trabalho, do que aprendi no curso de mestrado e/ou doutorado.

- As condições físicas do meu ambiente de trabalho (espaço, iluminação, mobiliário e outras) são adequadas à aplicação do que aprendi no meu mestrado e/ou doutorado.

- Tenho recebido elogios quando aplico corretamente, no trabalho, as novas competências que desenvolvi no curso de mestrado e/ou doutorado.

- Sou orientado, quando cometo erros ao aplicar as competências que desenvolvi no curso de mestrado e/ou doutorado.

- Sinto-me seguro em aplicar, no trabalho, o que aprendi no curso de mestrado e/ou doutorado.

- Considero-me motivado para utilizar, na situação de trabalho, as competências que desenvolvi no curso de mestrado e/ou doutorado.

\section{Dados do Funcionário Treinado}

- Gênero: masculino / feminino

- Minha última participação no Programa de Mestrado e Doutorado do Banco do Brasil foi em curso de: Mestrado / Doutorado

- Minha última participação no Programa de Mestrado e Doutorado do Banco do Brasil foi na condição de: Pesquisador com afastamento parcial do trabalho durante o curso / Bolsista sem afastamento do trabalho durante a realização de créditos do curso

- A conclusão do meu curso de mestrado e doutorado do Banco se deu há: 1 a 2 anos / 3 a 4 anos / 5 a 6 anos / 7 a 8 anos / 9 a 10 anos / 11 anos ou mais

Perspectivas em Gestão \& Conhecimento, João Pessoa, v. 8, n. 1, p. 155-190, jan./abr. 2018. 
- A área de conhecimento em que realizei meu curso de mestrado e/ou doutorado foi: Administração / Economia / Psicologia / Direito / Informática / Engenharia / outras

- Meu local de trabalho atual é: / Unidade de Negócios e Negócios Especializados (CABB, Agências Varejo, Atacado, Governo, Escritórios Private e Gerat) / Unidade de Apoio aos Negócios e à Gestão (AJURE, NUJUR, CSO, CSL, GEPES, GECEX etc) / Unidade Tática (Superintendência de Varejo e Governo, Comercial e GERET) / Unidade Estratégica (Diretorias, Unidades e Gerências Autônomas) / Outra (PREVI, CASSI, FBB etc)

- Minha função atual é: Escriturário / Gratificada do Segmento Técnico / Gratificada do Segmento Operacional / De confiança do Segmento de Assessoramento / De confiança do Segmento Gerencial 